\title{
Numerical Investigation of Injection-Induced Fracture Propagation in Brittle Rocks with Two Injection Wells by a Modified Fluid-Mechanical Coupling Model
}

\author{
Song Wang ${ }^{1,2,3}$, Jian Zhou ${ }^{4}\left(\mathbb{D}\right.$, Luqing Zhang ${ }^{1,3, *}$ and Zhenhua Han ${ }^{1,3}$ \\ 1 Key Laboratory of Shale Gas and Geoengineering, Institute of Geology and Geophysics, Chinese Academy \\ of Sciences, Beijing 100029, China; wangsong@mail.iggcas.ac.cn (S.W.); hanzhenhua@mail.iggcas.ac.cn (Z.H.) \\ 2 College of Earth and Planetary Sciences, University of Chinese Academy of Sciences, Beijing 100049, China \\ 3 Innovation Academy for Earth Science, Chinese Academy of Sciences, Beijing 100029, China \\ 4 Key Laboratory of Urban Security and Disaster Engineering, Ministry of Education, Beijing University \\ of Technology, Beijing 100124, China; zhoujian@mail.iggcas.ac.cn \\ * Correspondence: zhangluqing@mail.iggcas.ac.cn; Tel.: +86-10-8299-8642; Fax: +86-10-6201-0846
}

Received: 10 August 2020; Accepted: 7 September 2020; Published: 10 September 2020

\begin{abstract}
Hydraulic fracturing is a key technical means for stimulating tight and low permeability reservoirs to improve the production, which is widely employed in the development of unconventional energy resources, including shale gas, shale oil, gas hydrate, and dry hot rock. Although significant progress has been made in the simulation of fracturing a single well using two-dimensional Particle Flow Code (PFC2D), the understanding of the multi-well hydraulic fracturing characteristics is still limited. Exploring the mechanisms of fluid-driven fracture initiation, propagation and interaction under multi-well fracturing conditions is of great theoretical significance for creating complex fracture networks in the reservoir. In this study, a series of two-well fracturing simulations by a modified fluid-mechanical coupling algorithm were conducted to systematically investigate the effects of injection sequence and well spacing on breakdown pressure, fracture propagation and stress shadow. The results show that both injection sequence and well spacing make little difference on breakdown pressure but have huge impacts on fracture propagation pressure. Especially under hydrostatic pressure conditions, simultaneous injection and small well spacing increase the pore pressure between two injection wells and reduce the effective stress of rock to achieve lower fracture propagation pressure. The injection sequence can change the propagation direction of hydraulic fractures. When the in-situ stress is hydrostatic pressure, simultaneous injection compels the fractures to deflect and tend to propagate horizontally, which promotes the formation of complex fracture networks between two injection wells. When the maximum in-situ stress is in the horizontal direction, asynchronous injection is more conducive to the parallel propagation of multiple hydraulic fractures. Nevertheless, excessively small or large well spacing reduces the number of fracture branches in fracture networks. In addition, the stress shadow effect is found to be sensitive to both injection sequence and well spacing.
\end{abstract}

Keywords: hydraulic fracturing; discrete element method; modified fluid-mechanical coupling algorithm; injection sequence; well spacing; stress shadow effect

\section{Introduction}

With the rapid growth of the global economy, the conventional oil and gas resources with decreasing production cannot meet the need for energy. Unconventional energy resources such as shale gas, shale oil, gas hydrate, and dry hot rock geothermal energy are quite abundant, and their economically and technically feasible exploitation is an effective solution to the problem of future 
energy shortages [1-4]. However, extremely tight pore structure and ultra-low permeability for the unconventional reservoir rocks restrict the flow of energy and efficient production [5,6]. Hydraulic fracturing is an important technical method for reservoir reconstruction in the process of energy resources exploitation. By injecting high-pressure fluid into the reservoir, the rock is fractured, thereby increasing the conductivity [7-9]. Affected by the heterogeneity and anisotropy of the reservoir rock, the initiation and propagation of fractures, the leak-off of the fracturing fluid, the interaction between hydraulic fractures and natural fractures, and many other physical and mechanical conditions, hydraulic fracturing is generally regarded as the multi-field coupling problem under complex in-situ stress [10-13]. Mastering the mechanism of hydraulic fracturing technology is crucial to building a complex fracture network system and forming a high-yield unconventional energy reservoir.

Laboratory testing is a direct and effective method to discover the mechanism of hydraulic fracturing. Various observation and analysis techniques have been utilized by domestic and foreign geologists to study the fracturing behaviors of reservoir rocks under the action of pressure fluids [14-17]. Guo et al. [18] used the true triaxial test system and the high-energy computed tomography (CT) scanning based on linear accelerator to capture the effects of flow rate, in-situ stress and fluid viscosity on fracturing horizontal well in shale. They indicated that the abovementioned multi-aspect factors dominate the initiating and propagating rules of hydraulic fractures, and the interaction between hydraulic fractures and sedimentary bedding. Zhang et al. [19] observed the propagation patterns of supercritical carbon dioxide $\left(\mathrm{SC}-\mathrm{CO}_{2}\right)$ induced hydraulic fractures in shale through $\mathrm{CT}$ scanning and digital radiography (DR) scanning. Comparing with hydraulic fracturing, they believed that the percolation effect of $\mathrm{SC}-\mathrm{CO}_{2}$ reduces the initiation pressure needed to fractures by more than $50 \%$, and induces more secondary fractures to form complex fracture networks. He et al. [20] investigated the surface characteristics of hydraulic fractures using the scanning electron microscope (SEM), and found that numerous micro cracks propagating along the boundaries of hard minerals and soft organic matters connected the pores and macro hydraulic fractures, thus increasing the permeability of shale. Zhuang et al. [21] performed a set of hydraulic fracturing tests on granites under true triaxial loading with different injection schemes, and analyzed the mineral fracturing behaviors and induced seismicity according to thin section microscopic observations and acoustic emission technology. The results show that hydraulic fractures under six fluid injection schemes are all composed of the intragranular cracks splitting microcline, orthoclase and quartz, but the cyclic pulse pressurization scheme improves the injectivity and decreases induced seismicity.

In addition to these laboratory tests, low-cost and high-efficiency numerical simulation becomes one of the most common ways to solve the hydraulic fracturing problems as the computer science develops [22]. Various numerical simulation methods including the finite-element method (FEM), the finite-difference method (FDM), the discrete element method (DEM), and the discontinuous displacement method (DDM) are successful in reproducing the hydraulic fracturing process of reservoir rocks and revealing the mechanism of hydraulic fracture propagation [23,24]. Li et al. [25] simulated the multi-cluster hydraulic fracturing based on the FEM software ABAQUS, and demonstrated that stress interference from multiple-clusters causes the suppression and transfer of the fracture network. Liao et al. [26] stated that horizontal stress anisotropy plays a key role in the interaction between hydraulic fractures and natural fractures in term of the three-dimensional fracturing simulation by the FDM software FLAC 3D. Zangeneh et al. [27] established a conceptual reservoir model with faults in the DEM software UDEC to confirm the influence of fluid diffusion on triggering fault slip and to evaluate the maximum magnitude of seismic events. Janiszewski et al. [28] discussed the interaction of fractures in granite under different approach angle conditions with the help of the DDM software FRACOD, and concluded that the existence of low dip-angle fractures allows more complex fracture networks.

Each kind of numerical simulation software developed on the basis of the continuous or discontinuous methods has its own unique advantages. As a typical representative of DEM software, the numerical model created in PFC is composed of thousands of basic circular particles bonded together by the contact bonds [29]. Furthermore, the failure of a contact bond corresponds to the generation 
of a microcrack in the model. Because of the simple topology and the fast updating mechanism of particle information, PFC shows obvious advantages in emulating the initiation, propagation and aggregation of microcracks and the ultimate macro failure for rock and soil mass under complex stress conditions [30-33].

The fluid-mechanical coupling algorithm in PFC was first proposed by Cundall [34], which not only considers the interaction process of pore pressure and fracture aperture, but also realizes the fluid flow in both fractures and rock matrix. Al-Busaidi et al. [35] recreated the laboratory test results of hydraulic fracturing for Lac du Bonnet granite by simulation, which proved the effectiveness of this algorithm. Yoon et al. [36-38] probed into the seismic activity induced by fluid injection during the development of deep granite reservoir. The detailed seismic parameters involving temporal and spatial distribution, moment magnitudes and radiated seismic energy of the induced seismic events were obtained through the reservoir fracturing simulations, which provided constructive guidance for the optimization of field fracturing schemes. Tomac et al. [39,40] extended this algorithm and explored the influences of mineral grains, fluid pressure and temperature on permeable hot granite during injecting pressurized cold fluid. They presented that the thermal damage area of wellbore caused by rock cooling and cold fluid infiltration increases as the fluid dynamic viscosity decreases. In our previous research, the calculation method of fluid pressure in the domain after contact bond failure was modified to make the update of the simulation results more accurate when the numerical model contains a large-volume injection well $[41,42]$. Following the improved algorithm, we comprehensively studied the hydraulic fracturing mechanism in isotropic and laminated reservoirs under different in-situ stress state, injection rate and fluid viscosity, and validated the ability in modeling the variety of the interaction scenarios between hydraulic fractures and natural fractures such as direct crossing and crossing with an offset [43-47].

Although the PFC has been employed in many hydraulic fracturing studies, most of them only consider the simple case of single injection well and ignore the interference of the multiple injection wells. However, in order to obtain a better fracturing effect in the field of production, it is necessary to arrange multiple injection wells in a suitable space and select a reasonable fracturing sequence. In this study, taking the Alxa porphyritic granite as an example, a two-well fracturing model based on our modified algorithm was established to discuss the effects of injection sequence and well spacing on hydraulic fracturing behaviors. The rest of this paper is organized as follows. First, the characteristics of contact bond and the modified fluid-mechanical coupling algorithm in PFC were introduced. Second, the micromechanical parameters were carefully calibrated and validated according to the experimental results of uniaxial loading and the analytical solutions of the breakdown pressure, respectively. Third, the boundary conditions of the numerical model were transformed with reference to diverse schemes so as to analyze the change in breakdown pressure, fracture propagation pressure, fluid pressure distribution and fracture propagation pattern. Finally, the stress variation along the height direction of hydraulic fracture was extracted to assess the stress shadow effect of hydraulic fractures.

\section{Modeling Methodology}

\subsection{Introduction of Particle Flow Code}

PFC is a commercial DEM software that applies the rigid, unbreakable circular particles as the basic elements of the model. The circular particles in contact are available for connection as a whole by giving a contact bond model. During the process of solution, the displacements, contact forces and moments of particles are continuously updated with the calculation time by Newton's second law and force-displacement law until the unbalanced force and unbalanced moment in the model reach the program termination conditions [29].

Plentiful models of contact bonds built into PFC including the Parallel-Bond Model (PBM), the Smooth-Joint Model (SJM), the Flat-Joint Model (FJM) and the Hertz Contact Model (HCM) determine the macro mechanical properties of various solid materials [48]. In particular, envisioned 
as a collection of springs with constant strength and stiffness (Figure 1a), the PBM is mostly exerted into the simulations of rock materials by assigning the particle-interaction laws. Moreover, the normal component $F_{i}^{n}(t+\Delta t)$ and the tangential component $F_{i}^{s}(t+\Delta t)$ for the contact force and the contact moment $M(t+\Delta t)$ at time $t+\Delta t$ depend on the corresponding values at the start of the timestep with the increments. The detailed equations used are given by [43]:

$$
\begin{gathered}
F_{i}^{n}(t+\Delta t)=F_{i}^{n}(t)+\Delta F_{i}^{n}=F^{n}(t) n_{i}+\left(-k^{n} A \Delta U_{i}^{n}\right) n_{i} \\
F_{i}^{S}(t+\Delta t)=F_{i}^{S}(t)+\Delta F_{i}^{s}=F_{i}^{S}(t)+\left(-k^{s} A \Delta U_{i}^{s}\right) \\
M(t+\Delta t)=M(t)+\Delta M=M(t)+\left(-k^{n} I\right)\left(\omega^{[B]}-\omega^{[A]}\right) \Delta t
\end{gathered}
$$

where $k^{n}$ and $k^{s}$ are the normal and shear stiffness of the parallel bond, respectively; $\Delta U^{n}$ and $\Delta U^{s}$ are the relative normal-displacement increment and the relative shear-displacement increment in one timestep $\Delta t$, respectively; $\omega^{[A]}$ and $\omega^{[B]}$ are the relative rotation velocities of the two contacting particles, respectively; $n_{i}$ is the normal vector of each contact ( $i=1$ or 2 ); $A$ is the cross sectional area of the bond, and $I$ is the moment of inertia of the bond.
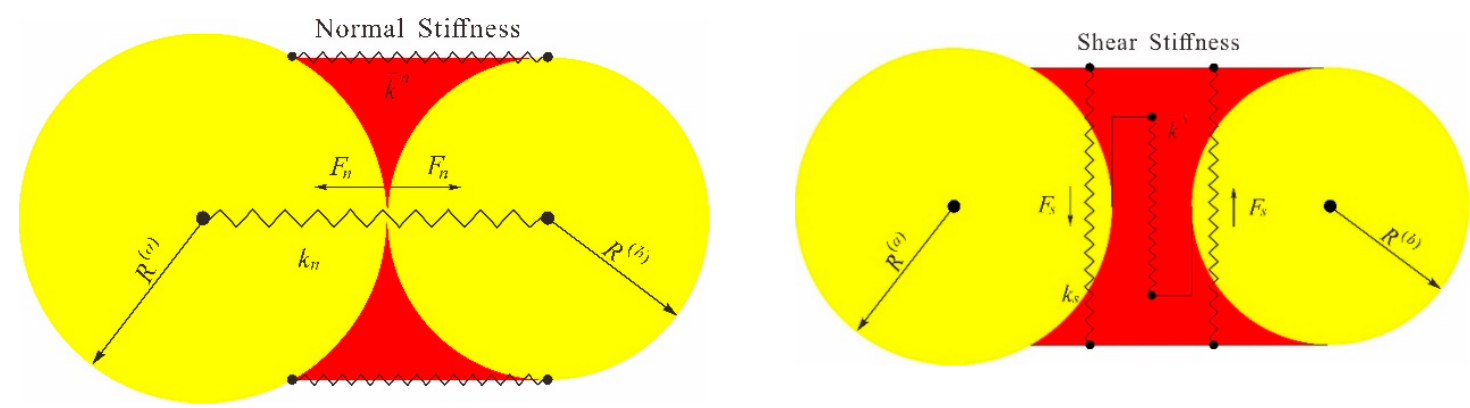

(a)

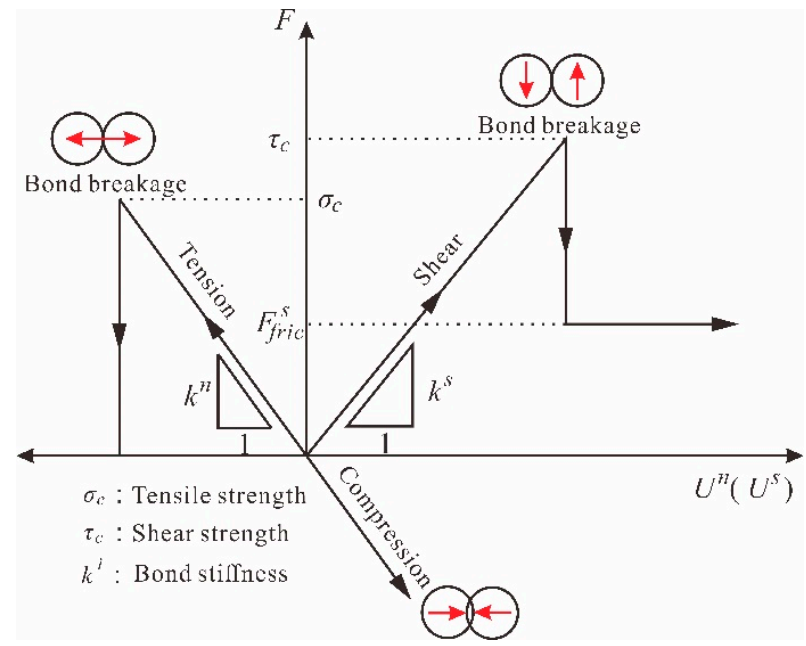

(b)

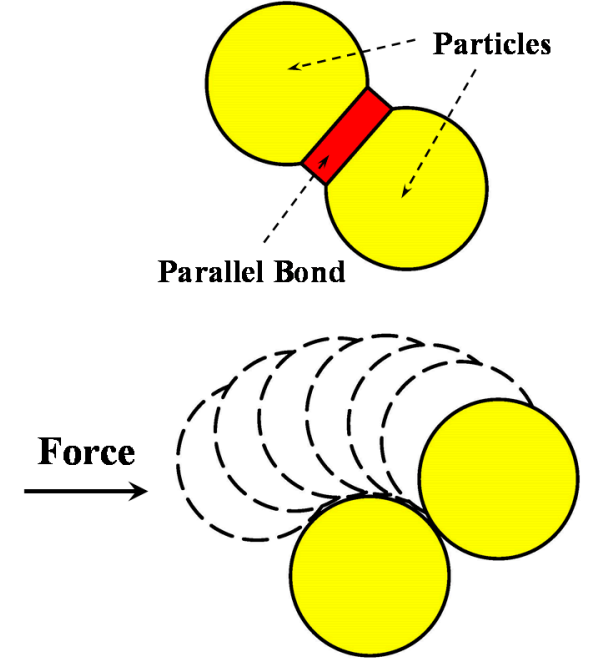

(c)

Figure 1. Schematic diagram of the Parallel-Bond contact in PFC2D (modified from Itasca Consulting Group, Inc.: Minneapolis, MN, USA [48]): (a) conceptual models; (b) the deformation and failure mechanisms; and (c) the failure mode.

Then the normal stress $\sigma$ and shear stress $\tau$ distributed on the cross-section of the bond are updated by the following equations [48]:

$$
\sigma=\frac{-F^{n}}{A}+\beta \frac{|M|}{I} R
$$




$$
\tau=\frac{\left|F_{i}^{s}\right|}{A}
$$

where $\beta$ is the moment-contribution factor.

At any time of solution, if the absolute value of normal stress $|\sigma|$ inside the bond exceeds the tensile strength of the bond $\sigma_{\mathrm{c}}$, or the absolute value of shear stress $|\tau|$ inside the bond exceeds the shear strength of the bond $\tau_{\mathrm{c}}$, the tensile failure or shear failure occurs respectively in the PBM (Figure $1 \mathrm{~b}$ ). Correspondingly, a tensile microcrack or a shear microcrack is generated in the numerical model. After the failure of the parallel bond, the force, moment, and stiffnesses related to the contact are removed, resulting in the rotation of the two particles around each other under external force (Figure 1c). Recent studies have pointed out that the rotation after the bond failure reduces the self-locking effect between the particles, causing an extremely low ratio of uniaxial compressive strength (UCS) to uniaxial tensile strength (UTS) [49,50]. Nonetheless, the PBM revised by potyondy [51] and Ding and Zhang [52] is still employed in this study, in which the moment-contribution factor $\beta$ is added to the bond failure criterion to overcome the above defects.

\subsection{Modified Fluid-Mechanical Coupling Algorithm}

Cundall's fluid-mechanical coupling algorithm achieves the flow of viscous fluid in the parallel bond. As illustrated in Figure 2a, the fluid network topology is constructed after the circular particles are assembled by the PBM. More specifically, connecting the centers of the contacting particles by blue lines forms a series of enclosed domains (blue polygons) which are regarded as "reservoirs" to store the fluid pressure. The centers of the adjacent reservoir domains (blue circles) are linked by the virtual pipes (magenta lines) to ensure fluid flow. Any pipe is approximated as two parallel plates existing in the parallel bond. A differential pressure between the two connected reservoir domains drives the flow of fluid from the high-pressure region to the low-pressure region. The volumetric flow rate $q$ is calculated by the cubic law [34]:

$$
q=\frac{e^{3}}{12 \mu} \frac{P_{2}-P_{1}}{L}
$$

where $e$ is the hydraulic aperture; $P_{2}-P_{1}$ is the fluid pressure difference between the reservoir domains; $L$ represents the length of the flow channel; $\mu$ is the fluid dynamic viscosity.

Under the action of confining pressure and fluid pressure, the hydraulic aperture $e$ changes with the normal stress $\sigma$ of the bond, which is described as [53,54]:

$$
e=e_{\mathrm{inf}}+\left(e_{0}-e_{\mathrm{inf}}\right) \exp (-0.15 \sigma)
$$

when $\sigma$ tends to infinity, the aperture decreases gradually to $e_{\text {inf; }}$; when $\sigma=0$, the aperture $e_{0}$ represents the residual aperture due to no force interaction between the particles on both sides of the flow channel. Therefore, this mechanism enables the fluid to diffuse into the surrounding reservoirs whether fractures are in the model. According to the Equation (8), the values of $e_{0}$ and $e_{\text {inf }}$ are determined by the permeability $k$, total volume $V$ of the reservoirs and flow channel length $L$ [35].

$$
k=\frac{1}{12 V} \sum_{\text {pipes }} L e^{3}
$$

In the fluid calculation process of one timestep, the increment of fluid pressure $\Delta P$ for a reservoir domain is derived from the apparent volume change of this domain $\Delta V_{d}$ and the fluid flow of surrounding reservoir domains $\Sigma q$, as shown in Equation (9) [43]:

$$
\Delta P=\frac{K_{f}}{V_{d}}\left(\sum q \Delta t-\Delta V_{d}\right)
$$

where $K_{f}$ is bulk modulus of fluid; $V_{d}$ is the apparent volume of the reservoir domain. 
After the fluid calculation step, the fluid pressure acts on the particles in the form of the body force (Figure $2 b$ ), and the magnitude of the force is the product of the fluid pressure $P_{f}$ and the length of the connecting line $l_{i}$ at the contact point. As the parallel bond between adjacent domains is broken owing to the effect of confining pressure and fluid pressure, Al-Busaidi et al. [35] and Zhao and Young [55] used the average value of the fluid pressures $P_{f 1}$ and $P_{f 2}$ in the two domains before bond failure to express the fluid pressure $P_{f}^{\prime}$ in the new domain:

$$
P_{f}^{\prime}=\frac{P_{f 1}+P_{f 2}}{2}
$$

Obviously, the Equation (10) is not suitable for the cases of large-volume injection well in the model because of the inaccurate average fluid pressure in the domains around the well. An optimized computing method is as follows [41]:

$$
P_{f}^{\prime}=\left[\frac{\left(V_{f 1}+V_{f 2}\right)}{\left(V_{r 1}+V_{r 2}\right) \varphi}-1\right] K_{f}
$$

where $V_{f 1}$ and $V_{f 2}$ are the fluid volume in the two domains before bond failure, respectively; $V_{r} 1$ and $V_{r} 2$ are the volume of the two domains under the fluid pressure of $0 \mathrm{MPa} ; \varphi$ is the porosity of the model.

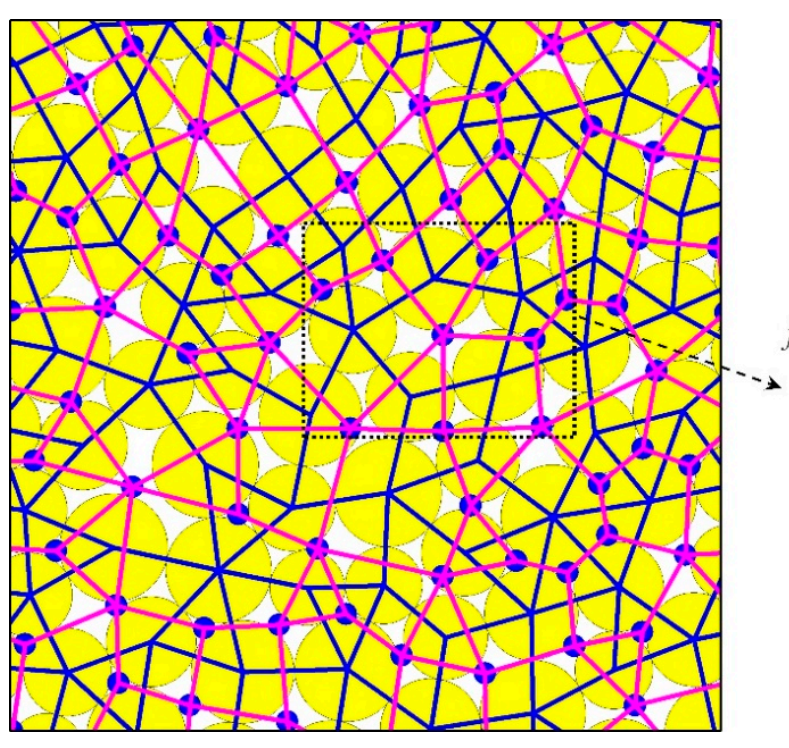

(a)

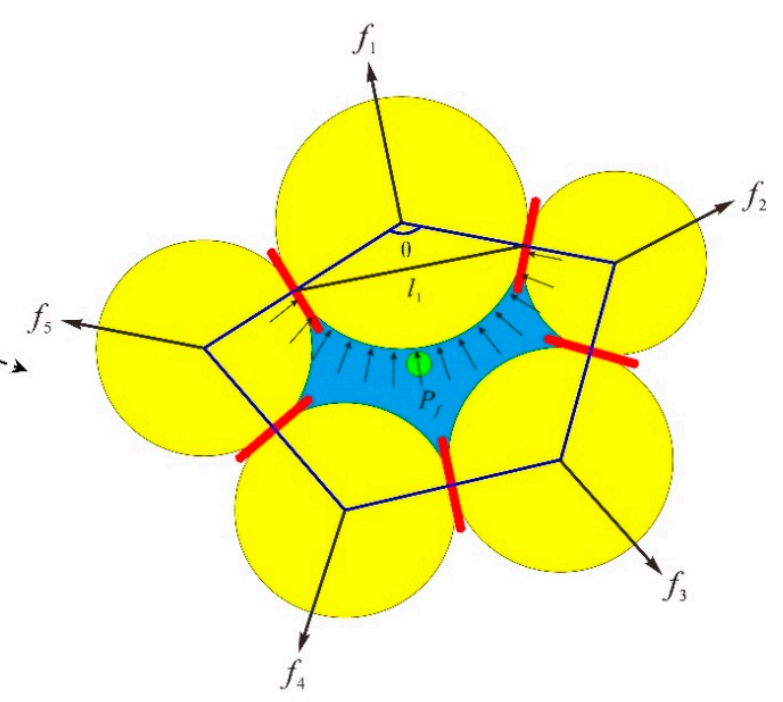

(b)

Figure 2. The sketch of the fluid-mechanical coupling model in PFC2D: (a) the generation of fluid network; and (b) fluid-particle interaction mechanism (yellow circles: solid particles, magenta lines: flow channels, blue polygons: reservoir domains, blue circles: the centers of reservoirs, red lines: Parallel-Bond contacts).

\section{Modeling Calibration and Validation}

The input micro-parameters involved in the fluid-mechanical coupling model in PFC2D are divided into three categories to characterize the physical and mechanical properties of basic particles, parallel bonds and fluid networks, most of which cannot be directly obtained from the laboratory tests. Debugging the parameters to match the calibration results with experimental results or analytical solutions is absolutely essential for the subsequent reliable numerical simulations. Fortunately, the relationships between the input parameters and macro mechanical characteristics of the models have been presented in several studies [56-59], which is helpful for the quick selection and calibration of the parameters. Combined with the uniaxial compression and tensile test results of Alxa porphyritic 
granite, a group of input parameters which reproduced the mechanical behaviors of the real granite under uniaxial loading were determined in this section. To verify the accuracy of the parameters in simulating hydraulic fracturing, the granite model with a single injection well were created and contrasted with the analytical solutions of the breakdown pressure.

\subsection{Laboratory Test}

As one of the preferred candidate locations for geological disposal of high-level radioactive waste, Alxa is located in the west of Inner Mongolia Autonomous Region, with the geographic coordinates of $97^{\circ} 10^{\prime} \sim 106^{\circ} 53^{\prime} \mathrm{E}$ and $37^{\circ} 24^{\prime} \sim 42^{\circ} 47^{\prime} \mathrm{N}$. The NRG-1 deep borehole in Alxa revealed that a large number of porphyritic granites are distributed from the surface to $600 \mathrm{~m}$ underground. The granitic cores from different depths of the borehole were processed into the standard specimens with a diameter of $50 \mathrm{~mm}$ and a height of $100 \mathrm{~mm}$. Before the uniaxial compression tests, the average density of the specimens was $2650.0 \mathrm{~kg} / \mathrm{m}^{3}$. During the testing, the MTS 815 servo-controlled hydraulic testing machine at the Institute of Crustal Dynamics, China Earthquake Administration was employed to compress the granites with an axial loading speed of $0.06 \mathrm{~m} / \mathrm{min}$.

The failure characteristics of Alxa porphyritic granites after the tests and the stress-strain curves are shown in Figures 3 and 4, respectively. It can be seen that all the specimens were cut by numerous splitting cracks, which conforms to the typical brittle fracturing pattern. The macro mechanical parameters of the specimens were extracted from the stress-strain curves, and the average values of the UCS, the elastic modulus (E) and the Poisson's ratio $(v)$ were $159.4 \mathrm{MPa}, 48.0 \mathrm{GPa}$ and 0.23 , respectively. The tensile test is not conducted in this research; however, the average UTS of this kind of granites is about 9.5 MPa according to our previous studies [60,61].


Figure 3. The failure characteristics of Alxa porphyritic granites after the uniaxial compressive tests.

\subsection{Material Parameters Calibration}

A rectangular numerical model with the same size as the test specimen was generated in PFC2D to emulate the uniaxial loading responses. The model was comprised of 10,412 circular particles with a radius distribution of $0.3-0.45 \mathrm{~mm}$ and was assigned the contact bonds of PBM. The effective modulus and stiffness of particles can inherit from the corresponding parameters of PBM. After the initial parameters were given, the simulations of uniaxial compression and direct tension were carried out to calculate the UCS, E, $v$ and UTS. Then the relevant parameters were continuously adjusted by the comparison between the experimental results and the simulated results. The final calibrated parameters are listed in Table 1, by which the simulated macro mechanical properties are in good agreement with the actual values, as shown in Table 2. The stress-strain curves and the spatial distribution of cracks are presented in Figure 4, which also proves the accuracy of parametric calibration. 


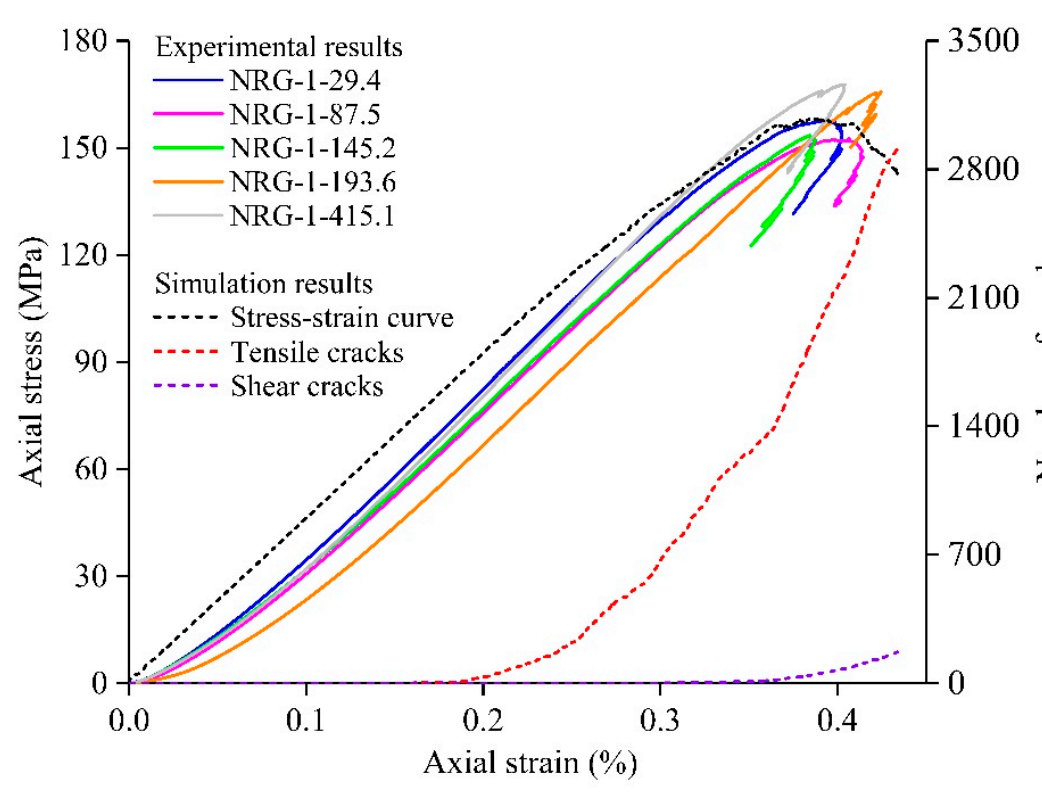

(a)

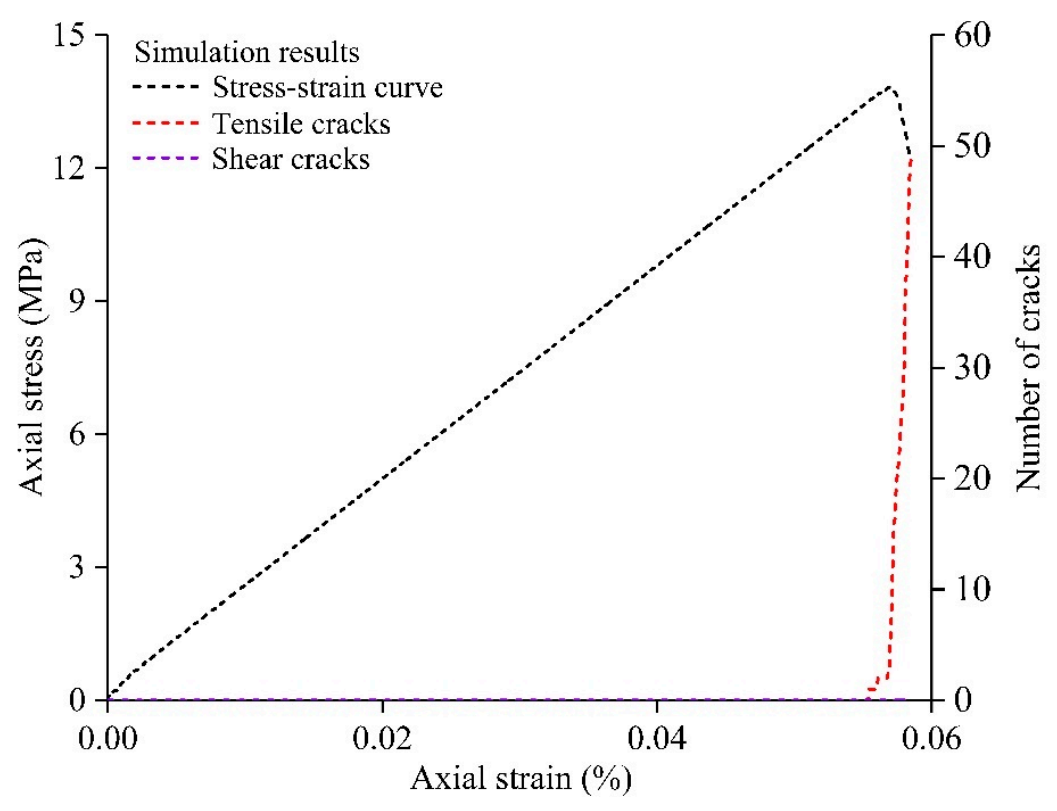

(c)

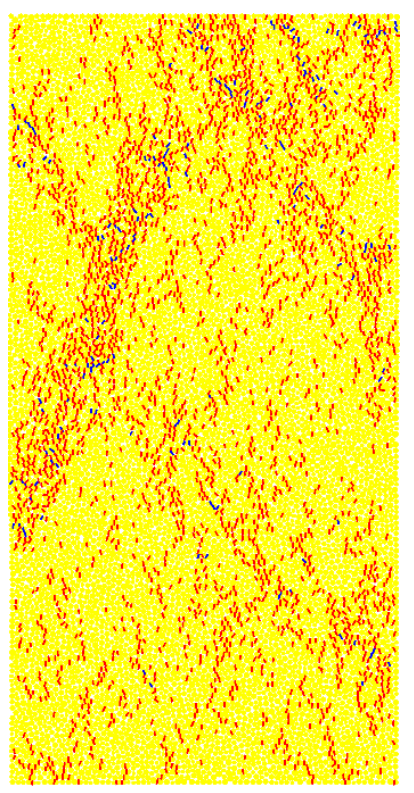

(b)

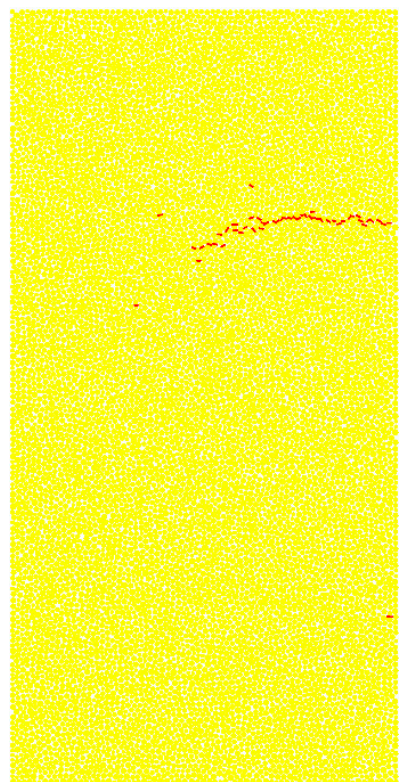

(d)

Figure 4. The simulated results under the calibrated parametric condition: (a) stress-strain curve and microcrack evolution under uniaxial compression; (b) microcrack distribution after uniaxial compression; (c) stress-strain curve and microcrack evolution under uniaxial tension; and (d) microcrack distribution after uniaxial tension.

Most of the microcracks generated in the numerical granite under the compressive loading are the tension-type modes. Fewer microcracks formed in the middle of model under the tensile loading, and aggregated into a macro fracture. 
Table 1. Calibrated Micro-Parameters in the Numerical Models of Alax Porphyritic Granite.

\begin{tabular}{ccc}
\hline Micro-Parameters of the Basic Particles & Notations & Values \\
\hline Particle density $\left(\mathrm{kg} / \mathrm{m}^{3}\right)$ & $\varrho$ & 2650.0 \\
Porosity $\%$ ) & $\varphi$ & 10 \\
Effective modulus of particle (GPa) & $E^{\prime}$ & 30.0 \\
Contact normal to shear stiffness ratio & $k_{\mathrm{n}} / k_{\mathrm{s}}$ & 1.5 \\
Friction coefficient of particle & $f$ & 0.8 \\
\hline Micro-Parameters of the Parallel Bonds & Notations & Values \\
\hline Effective modulus of the parallel bonds (GPa) & $E_{\mathrm{c}}$ & 30.0 \\
Normal to shear stiffness ratio of the parallel & $k^{\mathrm{n}} / k^{\mathrm{s}}$ & 1.5 \\
bonds & $\sigma_{\mathrm{c}}$ & 28.0 \\
Tensile strength of the parallel bonds (MPa) & $\tau_{\mathrm{c}}$ & 120.0 \\
Shear strength of the parallel bonds (MPa) & $\lambda$ & 1.0 \\
Radius multiplier & $\beta$ & 0.1 \\
Moment contribution factor & Notations & Values \\
\hline Micro-Parameters of the Hydraulic Properties & $e_{0}$ & $2.2 \times 10^{-6}$ \\
Initial hydraulic aperture (m) & $e_{\text {inf }}$ & $2.2 \times 10^{-7}$ \\
Infinite hydraulic aperture (m) & $k$ & $1.0 \times 10^{-17}$ \\
Model Permeability (m $\left.{ }^{2}\right)$ & $K_{f}$ & 2.0 \\
Bulk modulus of the fracturing fluid (GPa) & $\mu$ & $1.0 \times 10^{-3}$ \\
Viscosity of the fracturing fluid (Pa·s) & &
\end{tabular}

Table 2. Comparison of the Calibrated and Experimental Results of the Macro Mechanical Properties for Alax Porphyritic Granites.

\begin{tabular}{ccc}
\hline Macro Properties & Average of Experimental Results & Simulation Results \\
\hline UCS (MPa) & 159.4 & 159.7 \\
UTS (MPa) & $9.5^{1}$ & 13.8 \\
E (GPa) & 48.0 & 46.4 \\
$v$ & 0.23 & 0.21 \\
\hline
\end{tabular}

${ }^{1}$ The UTS of Alax porphyritic granite was acquired from Zhou et al. [60,61].

\subsection{Validation of Hydraulic Fracturing Model}

The fluid parameters for hydraulic fracturing were decided by the actual working conditions. After constructing the fluid networks and adding the fluid parameters in the PBM, it was still vital to verify whether the fracturing simulation could describe the realistic fracturing behaviors, including the breakdown pressure and the propagation of hydraulic fractures. A classical equation for the breakdown pressure $P_{w f}$ when the fluid is injected into a circular elastic borehole was proposed by Haimson and Fairhurst [62] as following expression:

$$
P_{w f}=3 \sigma_{v}-\sigma_{\mathrm{h}}-P_{0}+\sigma_{t}
$$

where $\sigma_{\mathrm{v}}$ is the confining pressure in vertical direction; $\sigma_{\mathrm{h}}$ is the confining pressure in horizontal direction; $P_{0}$ is initial pore pressure; $\sigma_{t}$ is the UTS of the model.

In order to facilitate the comparison of simulated and theoretical breakdown pressures and avoid the stress interference of multiple injection wells, the granite model with a single injection well was established, as shown in Figure 5a. The square fracturing model with a width and height of $1.0 \mathrm{~m}$ consisted of 11,778 circular particles with a radius distribution of 4-6 mm. Furthermore, the vertical and horizontal confining pressures were servo-controlled by moving the walls around the model. An injection well with a radius of $50 \mathrm{~mm}$ was excavated in the center of the model to inject viscous fluid. It is noted that the particles surrounding the injection well have been replaced by smaller particles to smooth the well surface and prevent stress concentration (Figure 5b). No fluid flow domains were covered on the border of the fracturing model to give the impermeable boundary 
conditions. The hydraulic apertures $e_{0}$ and $e_{\text {inf }}$ calculated by Equations (7) and (8) were $2.2 \times 10^{-6}$ and $2.2 \times 10^{-7}$, respectively, which were input into the model as basic hydraulic property parameters (Table 1). The fracturing fluid was the liquid water with a bulk modulus of $2.0 \mathrm{GPa}$ and a viscosity of $1.0 \times 10^{-3}$. The numerical model kept the vertical confining pressure $\sigma_{\mathrm{v}}$ and the horizontal confining pressure $\sigma_{\mathrm{h}}$ equal. Under the conditions of the initial pore pressure of $0 \mathrm{MPa}$ and the fluid injection rate of $1.0 \times 10^{-5} \mathrm{~m}^{3} / \mathrm{s}$, the hydraulic fracturing simulations with confining pressures from $5 \mathrm{MPa}$ to $50 \mathrm{MPa}$ (5-MPa intervals) were implemented.

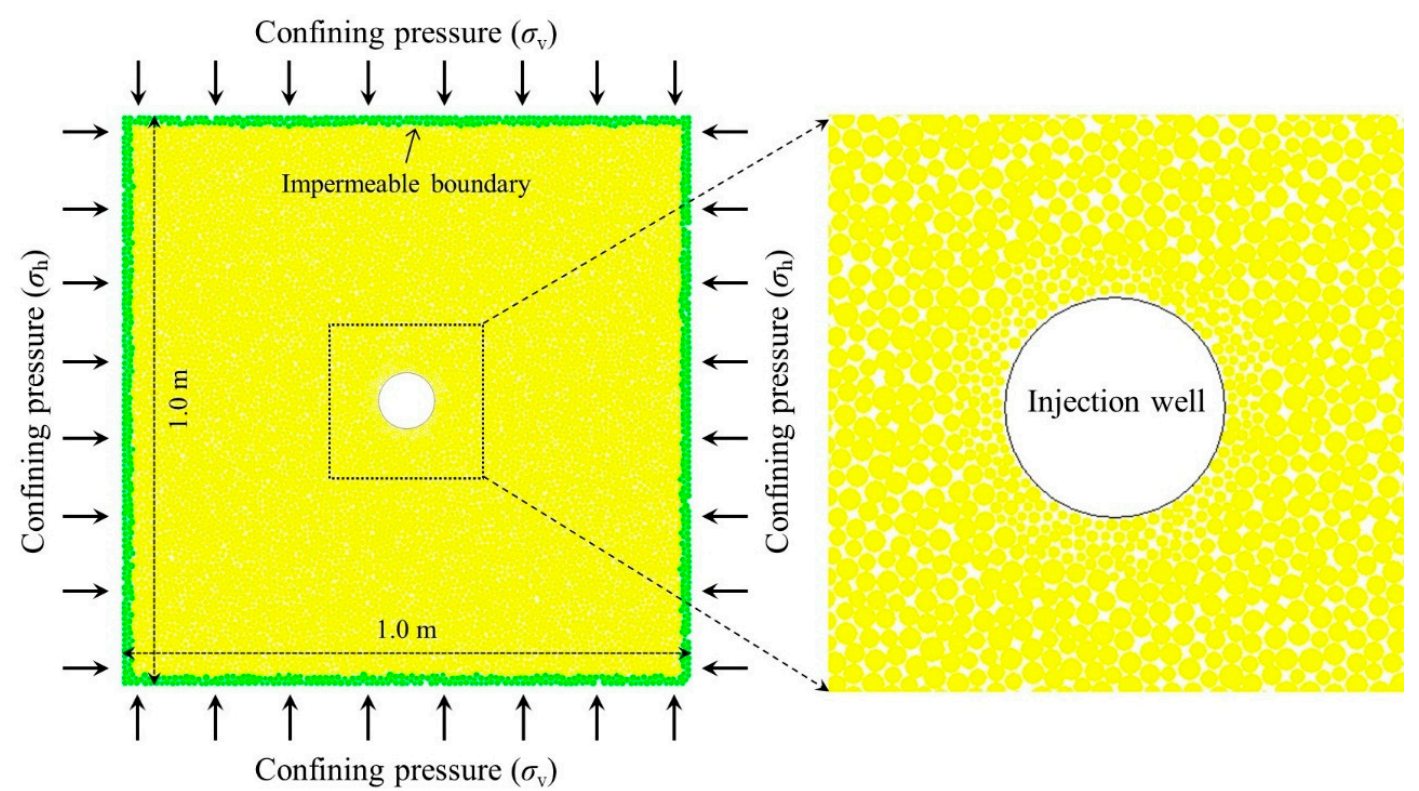

(a)

(b)

Figure 5. Granite model with a single injection well for hydraulic fracturing: (a) the model size and applied boundary conditions; and (b) particle densification near the injection well.

The simulated values and theoretical values of breakdown fractures are summarized in Figure 6, and the error between them is less than $20 \%$. The main reason for the deviation is that the analytical model assumes that the entire reservoir is impermeable, while the modified hydraulic fracturing model in PFC considers the leakage of fracturing fluid to the surrounding domains.

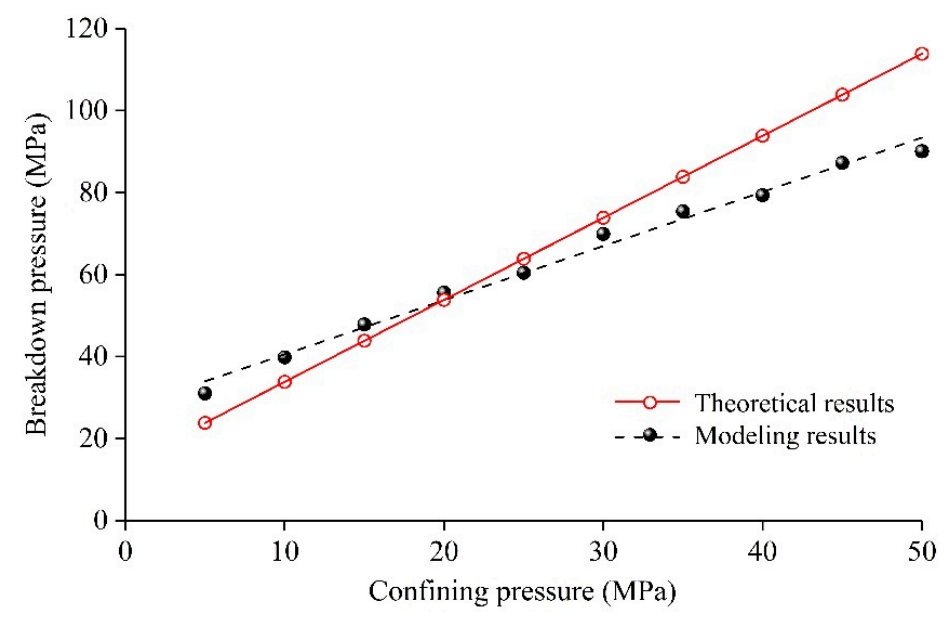

Figure 6. Comparison of breakdown pressures between the simulated values and the analytical solutions. 
Figure 7 shows the representative borehole pressure histories, crack spatial distribution and corresponding fluid pressure field in hydraulic fracturing under different confining pressures. It is found that the borehole pressure increases rapidly at the beginning of injection, and as the borehole pressure approaches the breakdown pressure, the borehole pressure increases slowly and non-linearly, which reflects that the leakage of fracturing faster is greater when the borehole pressure is high. The leakage of fluid from the injection well and fractures to the surrounding fluid networks can also be seen from the figures of the fluid pressure distribution.
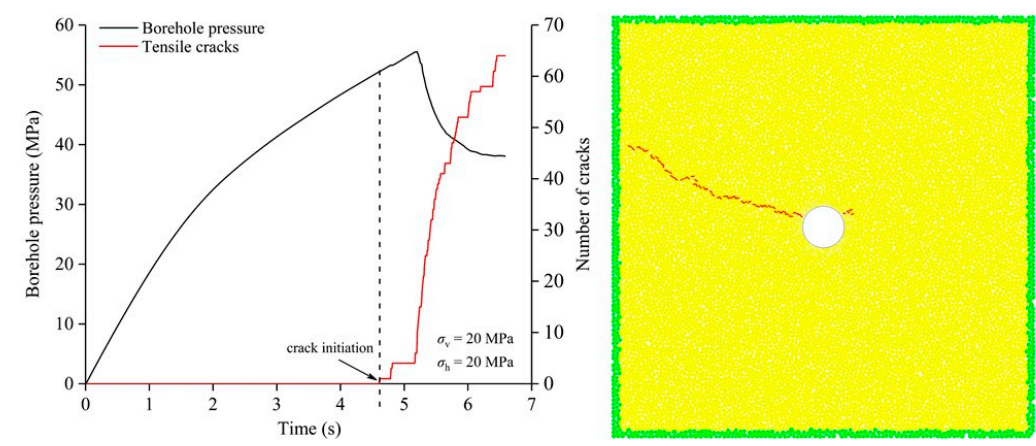

(a)
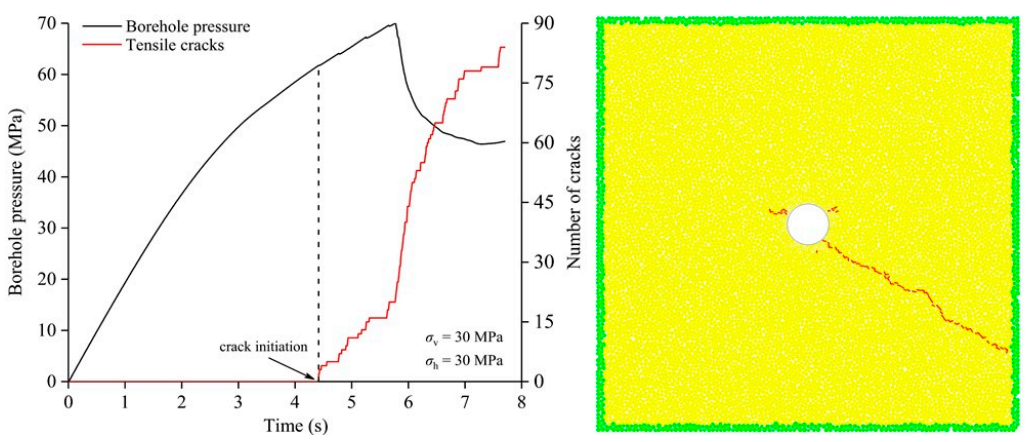

(b)
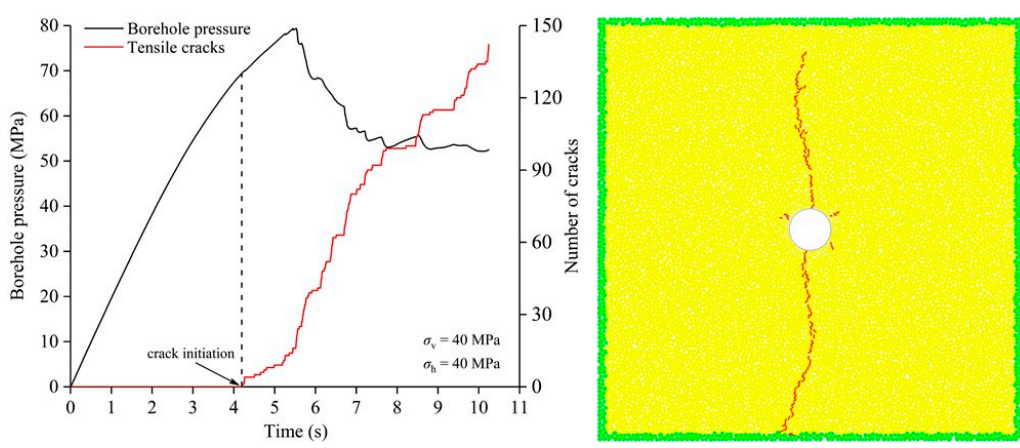

(c)
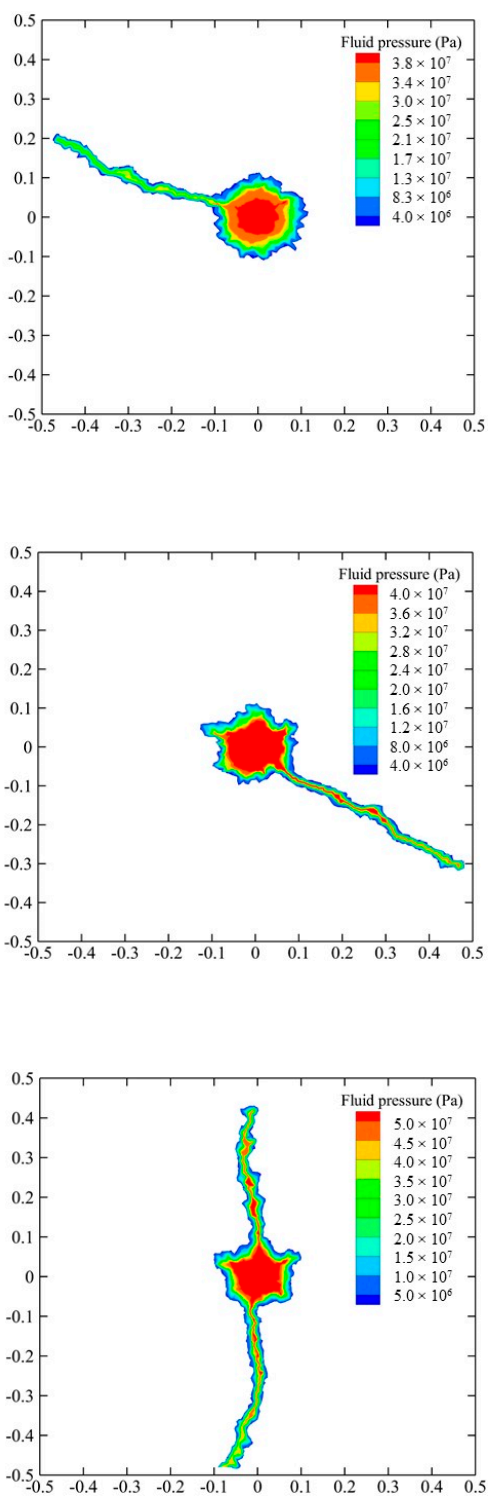

Figure 7. The representative borehole pressure histories, crack spatial distribution and corresponding fluid pressure field in the single-well fracturing under different in-situ stress conditions: $(\mathbf{a}) \sigma_{\mathrm{v}}=\sigma_{\mathrm{h}}$ $=20 \mathrm{MPa} ;(\mathbf{b}) \sigma_{\mathrm{v}}=\sigma_{\mathrm{h}}=30 \mathrm{MPa} ;$ and $(\mathbf{c}) \sigma_{\mathrm{v}}=\sigma_{\mathrm{h}}=40 \mathrm{MPa}$.

Before the borehole pressure reaches the breakdown pressure, a few cracks initiated around the wellbore. After increasing to the breakdown pressure, the borehole pressure dropped sharply to the fracture propagation pressure and remained unchanged. As a result, the number of microcracks grew dramatically along certain directions. Hubbert and Willis [63] proposed that the initiation and propagation of deep hydraulic fracturing fractures follow the direction of maximum principal stress. 
From Figure 7, we can see that the macro hydraulic fractures propagated along the different directions under various confining pressures. The difficulty in predicting the propagation direction stems from the fact that the micro defects on the surface of the injection well have more significant impact on the initiation and propagation of hydraulic fractures under hydrostatic pressure conditions.

Another noteworthy issue is that almost all the hydraulic fractures acquired from the fluid-mechanical coupling algorithm are made up of tensile cracks, which seems to be distinct from lots of shear-type seismic events observed in hydraulic fracturing tests for granite [64,65]. Al-Busaidi et al. [35] have demonstrated that the shear failures recorded in the laboratory tests are caused by the slippage of the preexisting cracks in the specimens, and the mechanism of injection-induced fracture is predominantly tensile failure. In brief, the simulation results of granite fracturing using the modified fluid-mechanical coupling algorithm are accurate.

\section{Hydraulic Fracturing Process in the Specimens with Two Injection Wells}

\subsection{Modeling Scenarios}

The multi-well hydraulic fracturing behaviors of reservoir rocks not only affected by the influencing factors of single-well fracturing (e.g., the mechanical properties of rocks, fluid injection rate, fluid viscosity and in-situ stress), but also by the influencing factors unique to multi-well fracturing (e.g., the number of injection wells, injection sequence and well spacing). Taking the two-well hydraulic fracturing process as the research object, a larger numerical model with a width of $1.5 \mathrm{~m}$ and a height of $1.0 \mathrm{~m}$, which was an aggregation of 17,700 circular particles, was constructed based on the fluid-solid coupling method introduced in Section 2 to get enough space to propagate for the fractures (Figure 8a). Two injection wells (Well No.1 and Well No.2) with the radius of $50 \mathrm{~mm}$ and the well spacing of L are symmetrical about the central axis of the model. After the calibration parameters in Table 1 were given in the two-well fracturing model, the influences of injection sequence and well spacing under different in-situ stress states on the breakdown pressure, fluid pressure distribution and hydraulic fracture propagation were discussed.

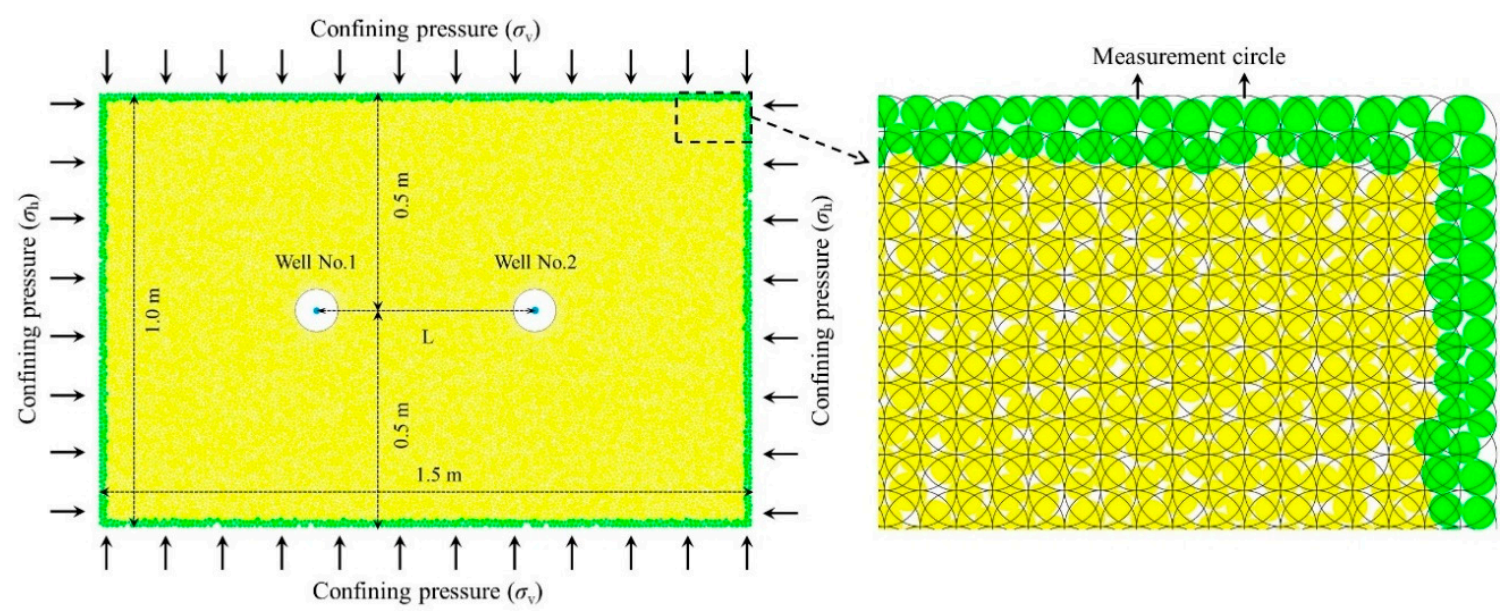

(a)

(b)

Figure 8. Granite model with two injection wells for hydraulic fracturing: (a) the model size and applied boundary conditions; and (b) arrangement of measurement circles.

\subsection{The Influence of Injection Sequence under Different In-Situ Stress Conditions}

The well spacing $\mathrm{L}$ of the two-well fracturing model was set to $0.5 \mathrm{~m}$. Three injection sequence schemes were designed for two water injection wells, which are: Scheme 1 -simultaneous injection in Well No.1 and Well No.2; Scheme 2-first injection in Well No.1 and second injection in Well No.2; 
and Scheme 3-first injection in Well No.2 and second injection in Well No.1. The fluid injection rate for each well was always $1.0 \times 10^{-5} \mathrm{~m}^{3} / \mathrm{s}$. If any hydraulic fracture propagates to the boundary of the model, the fluid injection and numerical simulation stop immediately, regardless of the shut-in stage in the field fracturing process. In the asynchronous fracturing of two injection wells, the second injection was conducted after the pore fluid pressure produced by the first injection was removed, so as to eliminate the effect of residual pore pressure.

The influence of different in-situ stresses was also considered in these injection schemes. When the model was under hydrostatic pressure, the vertical and horizontal confining pressures were fixed at 30 $\mathrm{MPa}$; when the maximum in-situ stress was in the horizontal direction, the vertical and horizontal confining pressures were fixed at $15 \mathrm{MPa}$ and $30 \mathrm{MPa}$, respectively. The three injection schemes have been repeatedly executed under each in-situ stress condition.

Figures 9-11 summarize the borehole pressure histories, crack spatial distribution and corresponding fluid pressure field for the fracturing of two-well granite model with the well spacing of $0.5 \mathrm{~m}$ under the hydrostatic pressure condition $\left(\sigma_{\mathrm{v}}=\sigma_{\mathrm{h}}=30 \mathrm{MPa}\right)$.

For the Scheme 1 of injection sequence, the borehole pressure curves recorded in Well No.1 and Well No.2 were nearly coincident in the process of simultaneous injection, and the breakdown pressures of the two wells were 62.0 MPa and 57.7 MPa (Figure 9). Similar to the fracturing of the single well, microcracks initially originated at the micro defects around the boreholes, and increased rapidly as the borehole pressures reduced to the fracture propagation pressure. However, the hydraulic fractures between the two wells were deflected at a large angle and close to each other during the propagations along the initial microcrack directions. Especially from the corresponding distribution of pore pressure field, it can be seen that the pore pressure field in the surrounding rock resulted from the fluid seepage in the two fractures will be superimposed on the tips. The other two hydraulic fractures were also considerably distorted until they propagated to the calculation boundary. In the end, four fracture branches formed in the model.
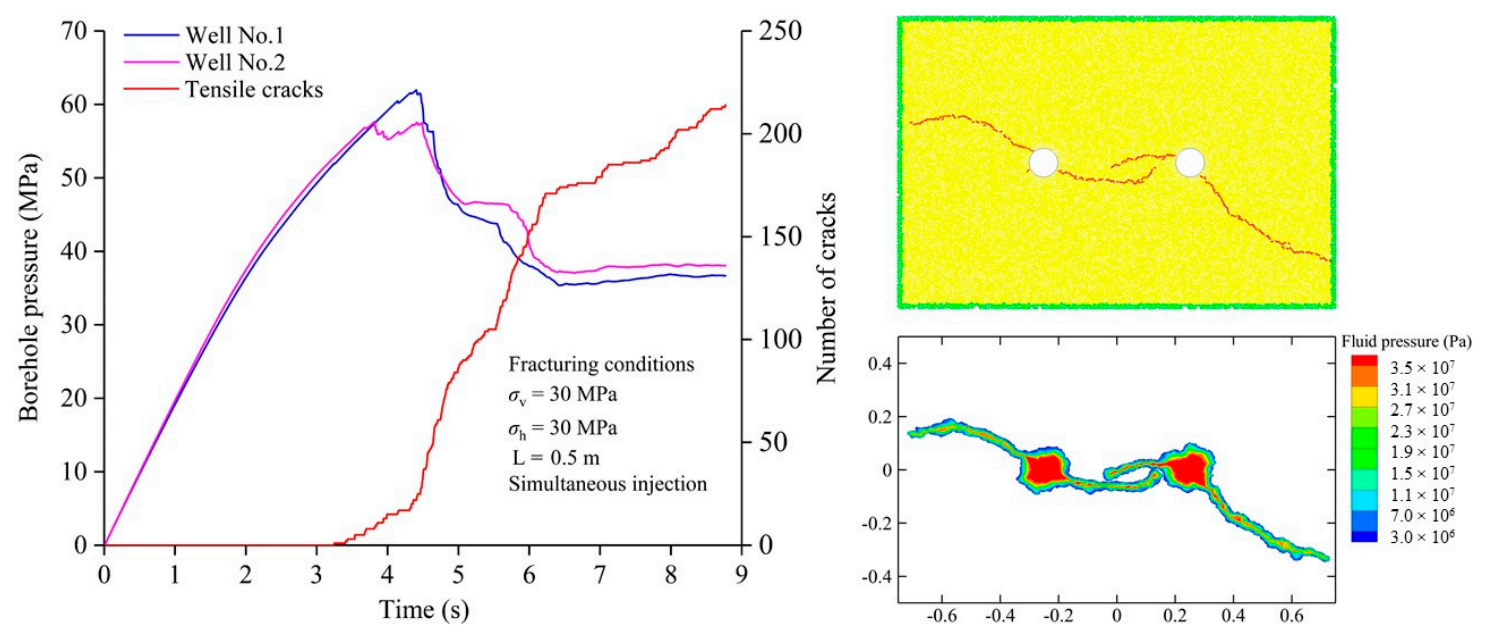

Figure 9. The borehole pressure histories, crack spatial distribution and corresponding fluid pressure field in the simultaneous fracturing under the hydrostatic pressure condition $\left(\sigma_{\mathrm{v}}=\sigma_{\mathrm{h}}=30 \mathrm{MPa}\right)$. 


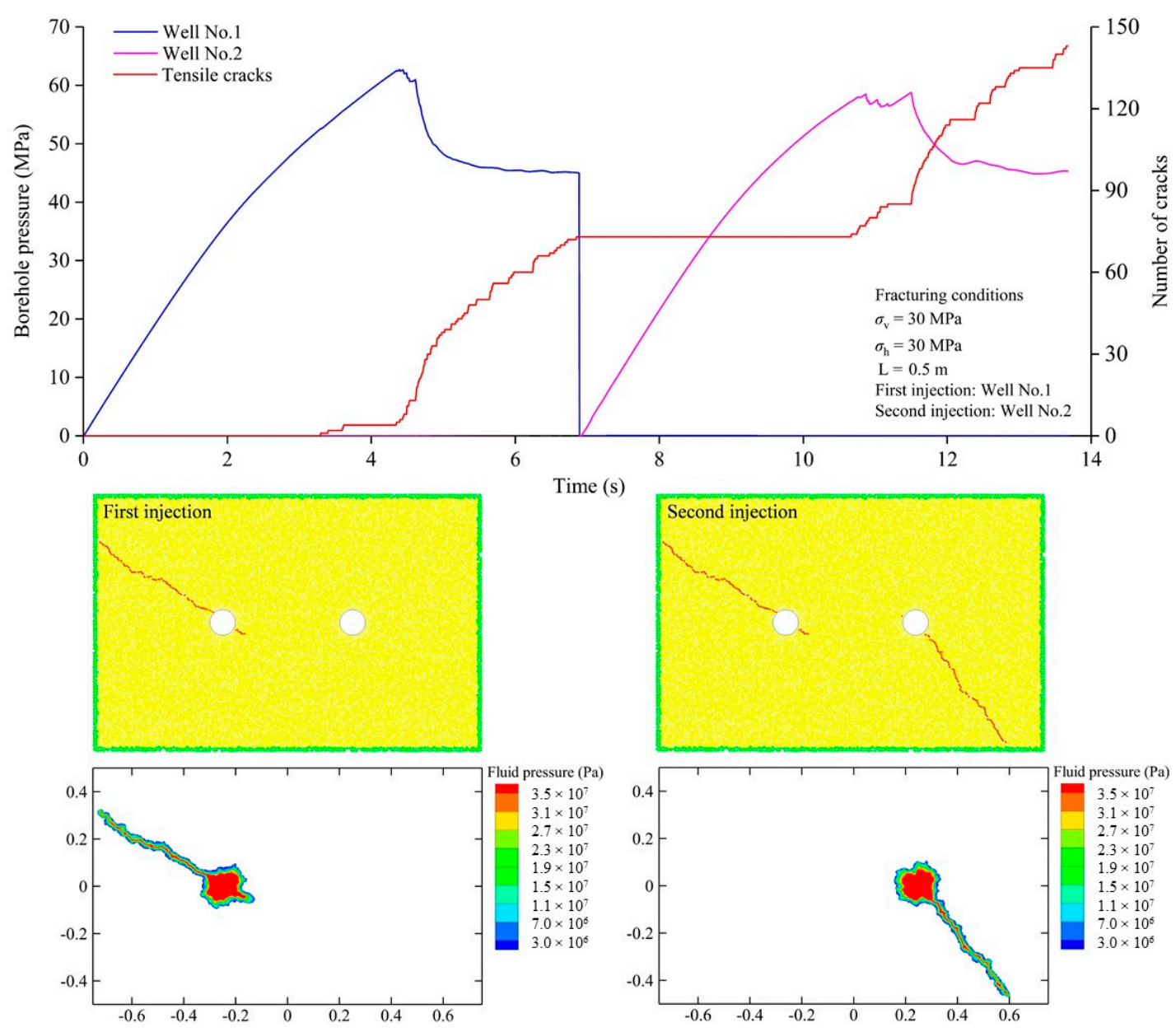

Figure 10. The borehole pressure histories, crack spatial distribution and corresponding fluid pressure field in the asynchronous fracturing (first injection: Well No.1 and second injection: Well No.2) under the hydrostatic pressure condition $\left(\sigma_{\mathrm{v}}=\sigma_{\mathrm{h}}=30 \mathrm{MPa}\right)$.

For the Scheme 2 of injection sequence, the breakdown pressures of Well No.1 and Well No.2 were 62.7 MPa and 58.8 MPa (Figure 10). After the first injection and the second injection, both hydraulic fractures in the left and right part of the model extended straight to the boundary at a high angle without distortion. Although the microcracks between the two injection wells were also initiated in the model, they did not propagate further.

For the Scheme 3 of injection sequence, the breakdown pressures of the two wells were $64.3 \mathrm{MPa}$ and 58.3 MPa (Figure 11). The final fracture propagation pattern was the same as that in the Scheme 2. The above simulation results may indicate that under the hydrostatic pressure condition, obvious differences between simultaneous injection and asynchronous injection exist in the fracturing behaviors, but the injection sequences in asynchronous fracturing has little effect on the generation of cracks. 


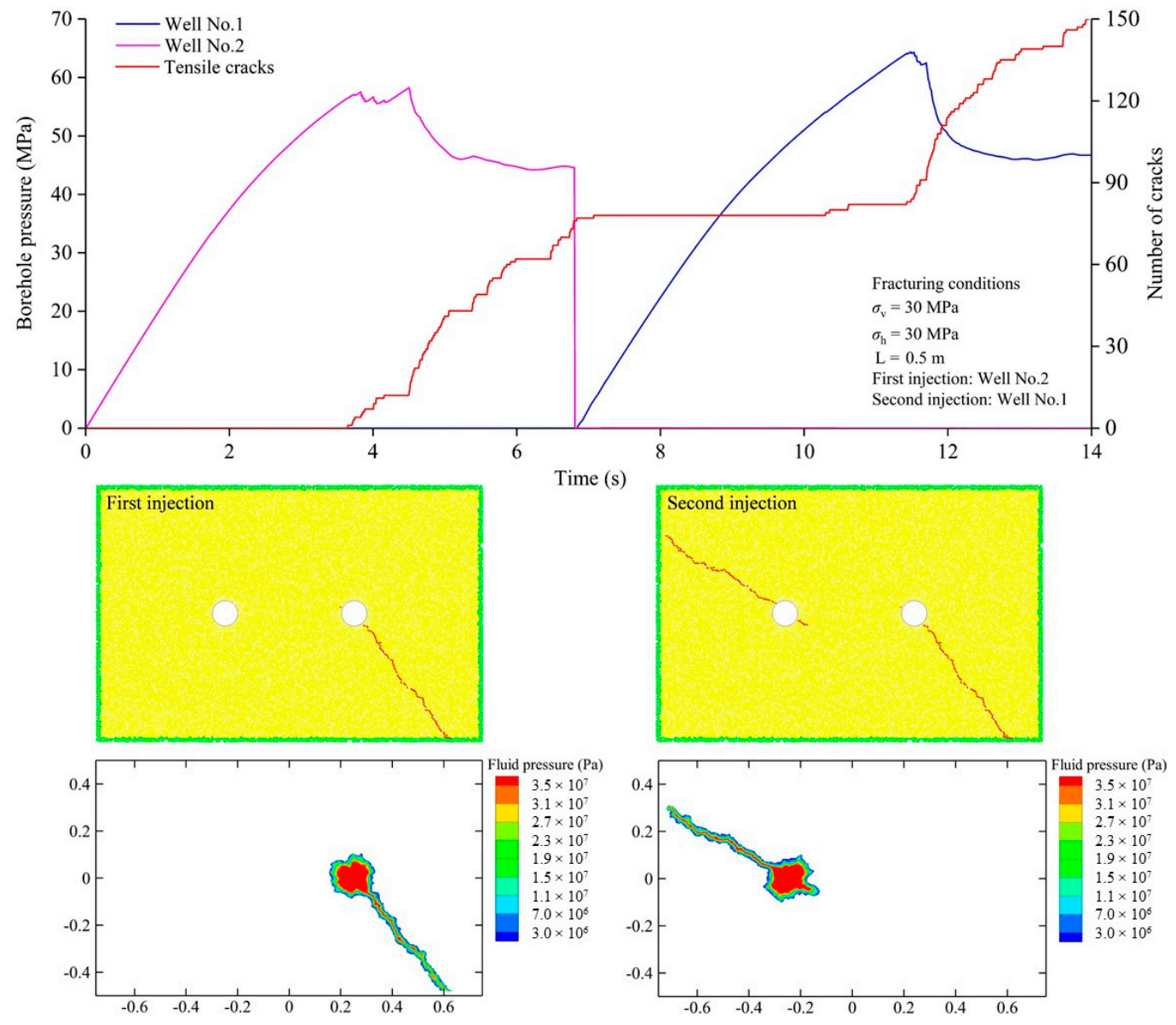

Figure 11. The borehole pressure histories, crack spatial distribution and corresponding fluid pressure field in the asynchronous fracturing (first injection: Well No.2 and second injection: Well No.1) under the hydrostatic pressure condition $\left(\sigma_{\mathrm{v}}=\sigma_{\mathrm{h}}=30 \mathrm{MPa}\right)$.

Figures 12-14 present the borehole pressure histories, crack spatial distribution and corresponding fluid pressure field under the conditions of the three injection schemes when $\sigma_{\mathrm{v}}=15 \mathrm{MPa}$ and $\sigma_{\mathrm{h}}=30 \mathrm{MPa}$. The breakdown pressures of the two wells were slightly reduced compared with those under hydrostatic pressure.
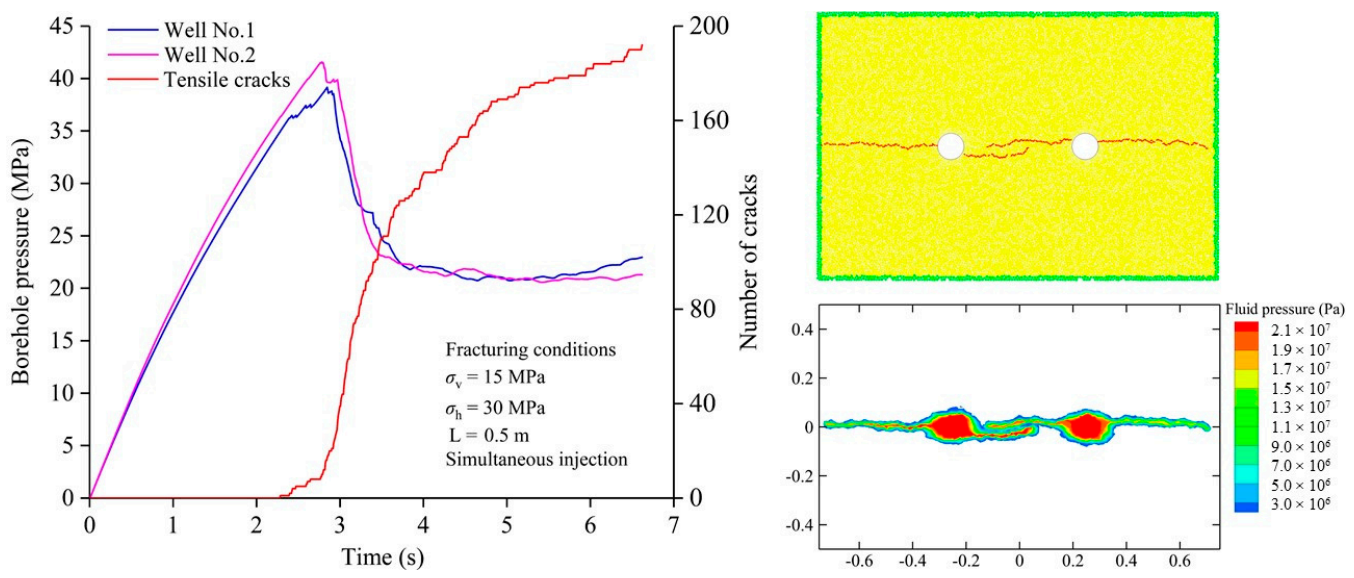

Figure 12. The borehole pressure histories, crack spatial distribution and corresponding fluid pressure field in the simultaneous fracturing under the in-situ differential stress condition $\left(\sigma_{\mathrm{v}}=15 \mathrm{MPa}\right.$ and $\left.\sigma_{\mathrm{h}}=30 \mathrm{MPa}\right)$. 


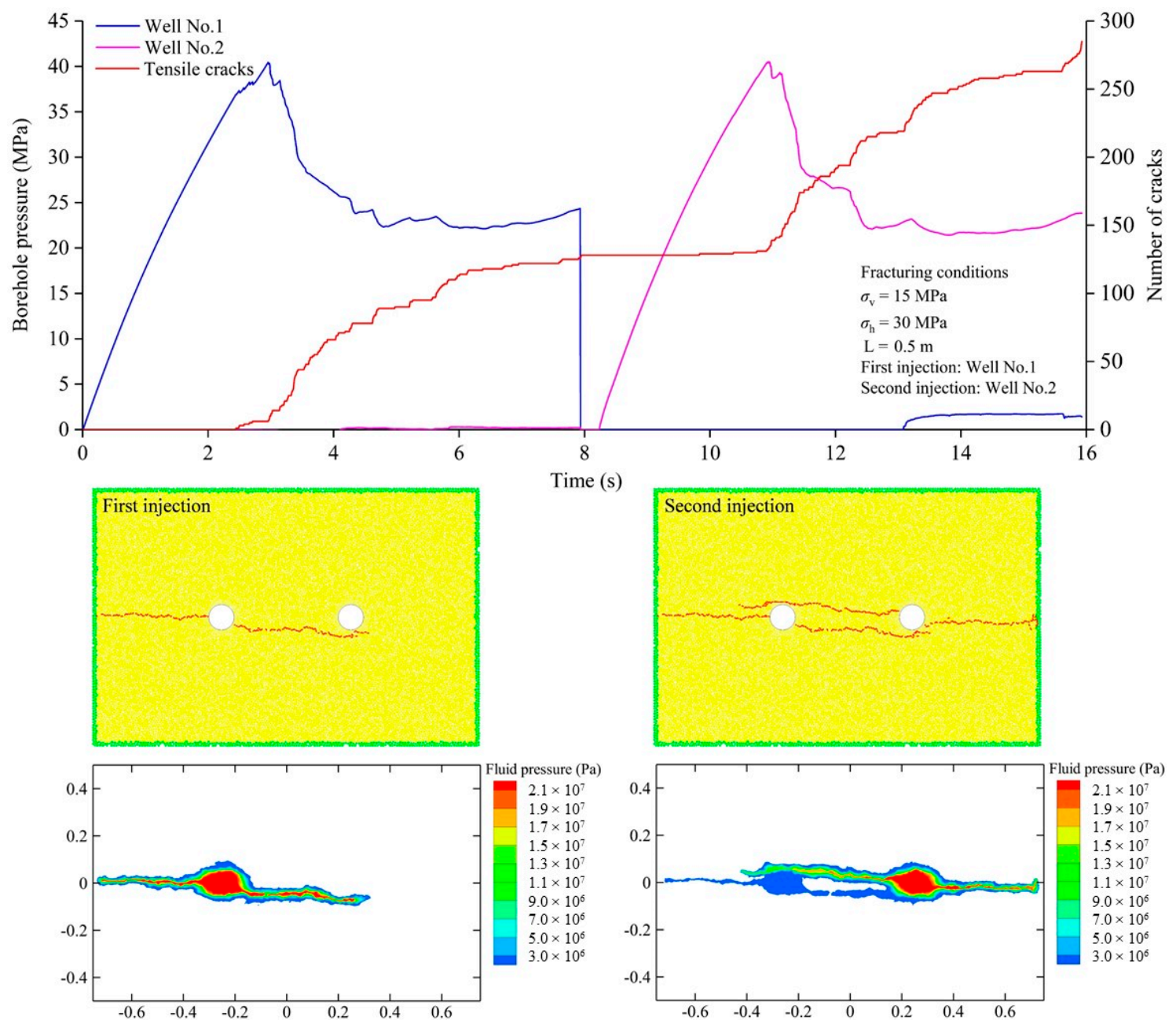

Figure 13. The borehole pressure histories, crack spatial distribution and corresponding fluid pressure field in the asynchronous fracturing (first injection: Well No.1 and second injection: Well No.2) under the in-situ differential stress condition $\left(\sigma_{\mathrm{v}}=15 \mathrm{MPa}\right.$ and $\left.\sigma_{\mathrm{h}}=30 \mathrm{MPa}\right)$.

In-situ differential stress gave rise to the propagations for the four hydraulic fractures along the horizontal direction in the simultaneous fracturing (Figure 12). The fractures between the two wells were not at the identical height, yet had a tendency to deflect and merge.

After the fracturing of Well No.1 in the Scheme 2, two hydraulic fractures extended along the horizontal direction to both sides of the borehole (Figure 13). The propagation pattern of the left hydraulic fracture was entirely consistent with that in simultaneous fracturing. Interestingly, the right hydraulic fracture was not bent and extended straight through the bottom of Well No.2. From the borehole pressure history and pore pressure distribution, it seems that Well No.2 was isolated from the hydraulic fracture as before. Stopping the injection in Well No.1 and continuing to fracture the Well No.2, the other two hydraulic fractures were produced along the horizontal direction. Due to the interference of the existing hydraulic fractures, the initiation position of the new fracture in the right part of the model has been changed in contrast to the fracture simulated by the Scheme 1. At about $13 \mathrm{~s}$ of the simulation time, a fluid pressure of 1.8 MPa was observed in Well No.1, which implies that the new hydraulic fracture between the injection wells extended from Well No.2 has been connected with Well No.1. A large quantity of fracturing fluid flowed into the Well No.1 through this fracture, and further migrated to fill the hydraulic fractures generated by the first fracturing. The four fracture branches in the model aggravated the leakage of fluid to the surrounding formation and prevented the borehole pressure of Well No.1 from increasing. 

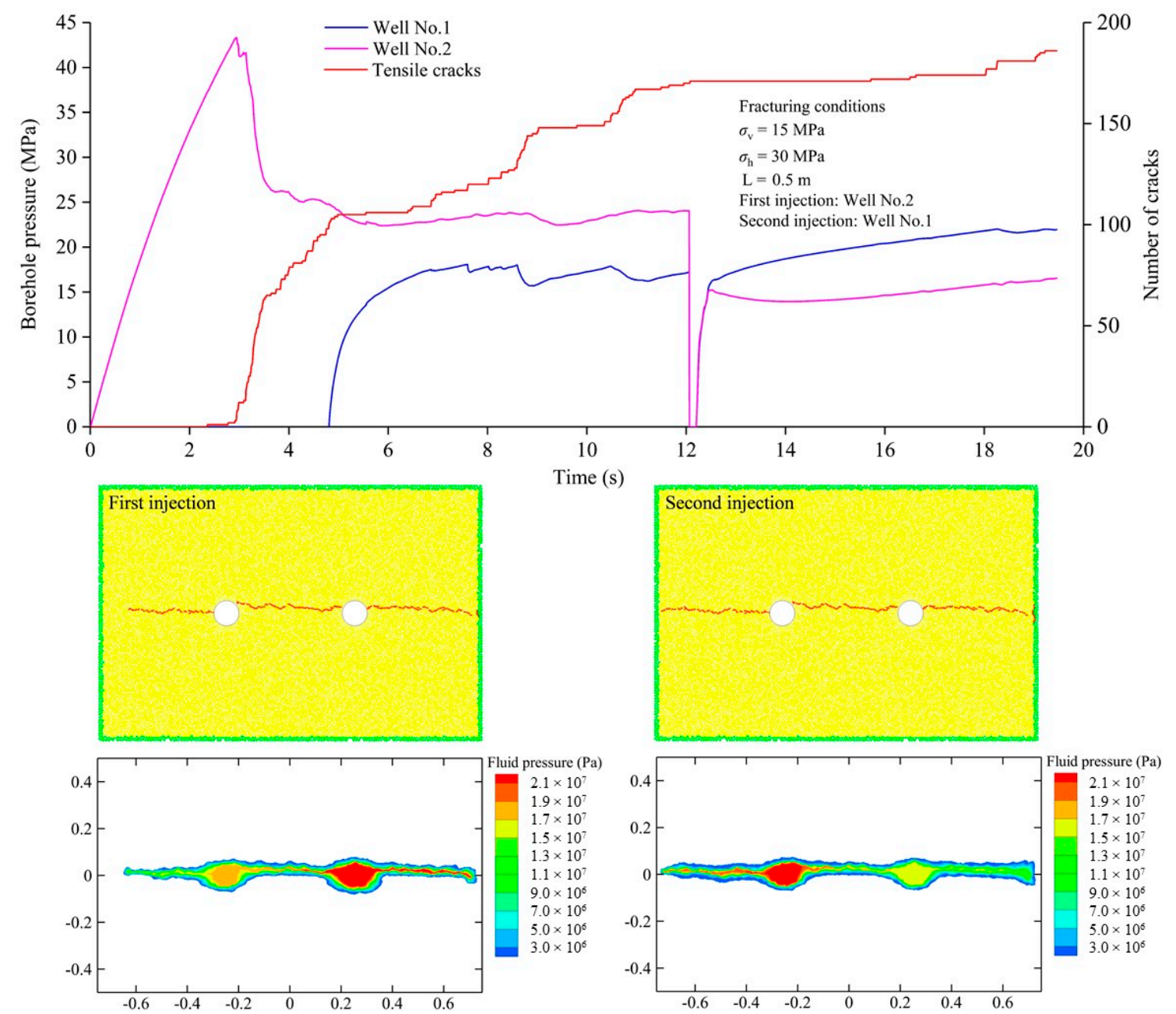

Figure 14. The borehole pressure histories, crack spatial distribution and corresponding fluid pressure field in the asynchronous fracturing (first injection: Well No.2 and second injection: Well No.1) under the in-situ differential stress condition $\left(\sigma_{\mathrm{v}}=15 \mathrm{MPa}\right.$ and $\left.\sigma_{\mathrm{h}}=30 \mathrm{MPa}\right)$.

The breakdown pressure of the Well No.2 was $43.3 \mathrm{MPa}$ in the Scheme 3 (Figure 14). Unlike the fracturing in the Scheme 1 and Scheme 2, the hydraulic fracture between the two wells directly penetrated into the Well No.1 during the first injection, so that the borehole pressure of Well No.1 gradually rose to approximately $17 \mathrm{MPa}$. It is noteworthy that a new hydraulic fracture emerged from the outside of Well No.1 and propagated to the left edge of the model without reaching the previous breakdown pressures. This may be attributed to two aspects: on the one hand, the seepage of fracturing fluid has increased the pore fluid pressure and decreased the effective stress of the granite model; on the other hand, the rate of the fluid injection from Well No.2 into Well No.1 through the fracture was relatively low, which provided enough time for the stress of the solid framework around the Well No.1 to adjust. Additionally, the fluid pressure was found to decay steeply when flowing in the fractures on the left side of Well No.2. In the absence of sufficient fluid pressure, the propagation speed of the corresponding fractures was slow. During the second injection, the existing hydraulic fractures induced the fracturing fluid leak into the surrounding rock and limited the growth of borehole pressures for two wells. For example, the borehole pressure of Well No.1 was maintained near the fracture propagation pressure, which promoted the hydraulic fracture in the left part of the model to extend to the edge, but inhibited the generation of new hydraulic fracture.

The breakdown pressure, fracturing propagation pressure, crack number and hydraulic fracture branches after the fracturing under different in-situ stress states are listed in Table 3. In any injection 
sequence scheme, before the borehole pressure increased to the breakdown pressure, the fluid injected into the wells had no time to migrate in large area. Consequently, no evidence was found for the clear correlation between the breakdown pressure and injection sequence. As more fluid seeped into the rock matrix in the simultaneous injection, the effective stress between particles was markedly weakened, making the fluid pressure required for hydraulic fracture propagation lower than that in asynchronous fracturing. In the process of asynchronous fracturing, if the hydraulic fractures induced in the first injection have penetrated into the well for the second injection, the fluid pressure in the second injection well was hold at the fracture propagation pressure and the fractures extended tardily.

Table 3. Summary of the Fracturing Characteristics for the Two-Well Granite Model with the Well Spacing of $0.5 \mathrm{~m}$ under Different Injection Sequences.

\begin{tabular}{|c|c|c|c|c|c|c|c|}
\hline $\begin{array}{l}\text { In-Situ Stress } \\
\text { Conditions }\end{array}$ & $\begin{array}{l}\text { Hydraulic Fracturing } \\
\text { Characteristics }\end{array}$ & \multicolumn{2}{|c|}{ Scheme 1} & \multicolumn{2}{|c|}{ Scheme 2} & \multicolumn{2}{|c|}{ Scheme 3} \\
\hline \multirow{3}{*}{$\begin{array}{l}\sigma_{\mathrm{v}}=30 \mathrm{MPa} \\
\sigma_{\mathrm{h}}=30 \mathrm{MPa}\end{array}$} & $\begin{array}{c}\text { Breakdown pressure } \\
(\mathrm{MPa})\end{array}$ & 62.0 & 57.7 & 62.7 & 58.8 & 64.3 & 58.3 \\
\hline & $\begin{array}{l}\text { Fracture extension } \\
\text { pressure }(\mathrm{MPa})\end{array}$ & 36.7 & 38.1 & 45.3 & 44.8 & 46.2 & 44.6 \\
\hline & Crack number & \multicolumn{2}{|c|}{214} & \multicolumn{2}{|c|}{145} & \multicolumn{2}{|c|}{149} \\
\hline \multirow{3}{*}{$\begin{array}{l}\sigma_{\mathrm{v}}=15 \mathrm{MPa} \\
\sigma_{\mathrm{h}}=30 \mathrm{MPa}\end{array}$} & $\begin{array}{l}\text { Breakdown pressure } \\
(\mathrm{MPa})\end{array}$ & 39.2 & 41.6 & 40.4 & 40.5 & - & 43.3 \\
\hline & $\begin{array}{l}\text { Fracture extension } \\
\text { pressure }(\mathrm{MPa})\end{array}$ & 20.8 & 20.7 & 22.3 & 21.7 & 16.5 & 23.6 \\
\hline & Crack number & \multicolumn{2}{|c|}{192} & \multicolumn{2}{|c|}{285} & \multicolumn{2}{|c|}{186} \\
\hline
\end{tabular}

Overall, the propagations of the hydraulic fractures between the two wells can be divided into four modes: (1) extending linearly and directly penetrating the two wells; (2) extending linearly at different heights without connection; (3) extending at certain deflection angles and merging at the tips; (4) suspending the extension after initiation. Mode (2) and (3) are suggested to improve the complexity of fracture networks. By comparing the hydraulic fracture propagation modes for the three schemes, both simultaneous fracturing and asynchronous fracturing under different in-situ stresses were observed to have the ability to form multiple fracture branches, which depended on the superposition of fluid pressures. Under the hydrostatic pressure condition, the initial expansion direction of hydraulic fractures in the asynchronous fracturing is affected by the micro-defects around the borehole, largely leading to no fractures between the two wells. In contrast, simultaneous fracturing reduces the effective stress of the rock matrix and forces the hydraulic fractures to extend to this region. When the maximum in-situ stress is in the horizontal direction, the initial expansion direction of hydraulic fractures is also along the horizontal direction. In this case, simultaneous fracturing intensifies the coalescence of the fractures between the two wells and simplifies the fracture networks. Therefore, selecting the reasonable injection sequence according to the in-situ stress condition is necessary for stimulating reservoir to produce more hydraulic fractures.

\subsection{The Influence of Well Spacing under Different In-Situ Stress Conditions}

The two-well fracturing models with the well spacing $\mathrm{L}$ of $0.3 \mathrm{~m}, 0.4 \mathrm{~m}$ and $0.6 \mathrm{~m}$ were established respectively, and the micro mechanical parameters, permeability, injection rate and in-situ stress conditions consistent with those in Section 4.2 were allocated to the models. Simultaneous fracturing was conducted on each model without considering the influence of injection sequence. Figures 15 and 16 show the fracturing simulation results of the granite models with diverse well spacing under different in-situ stress conditions. Refer to Figures 9 and 12 for the simultaneous fracturing results when the well spacing is $0.5 \mathrm{~m}$. 

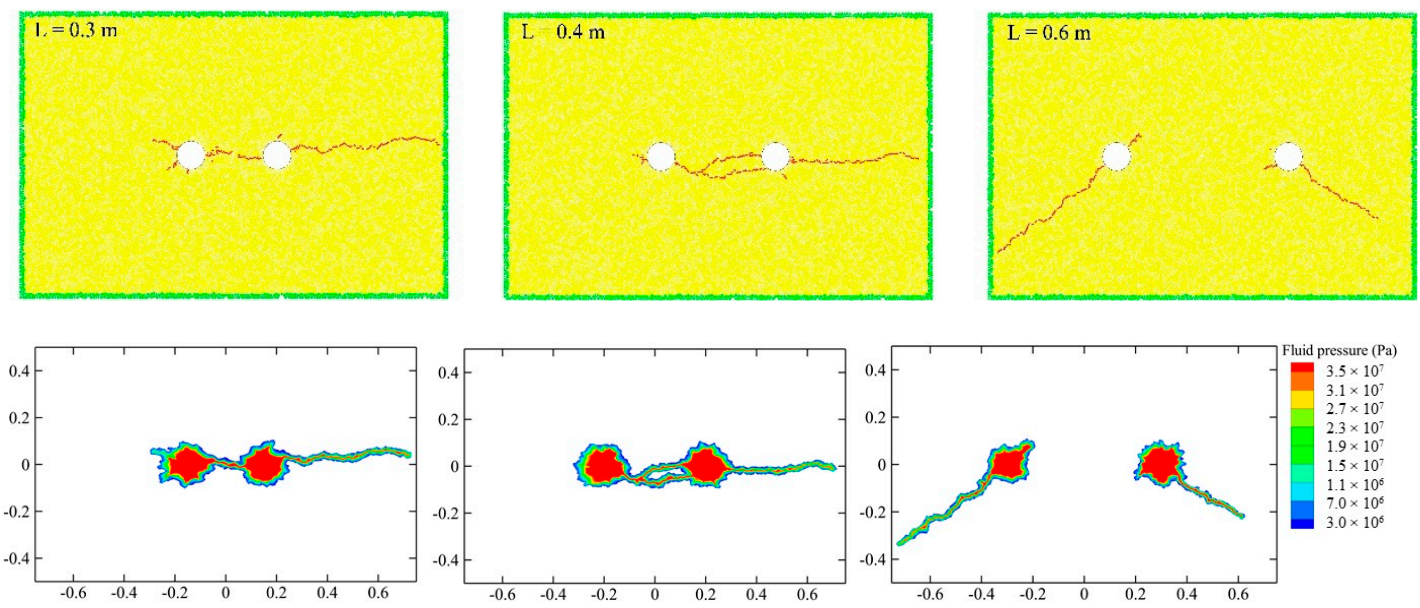

Figure 15. The crack spatial distributions and corresponding fluid pressure fields for the two-well granite models with the well spacing of $0.3 \mathrm{~m}, 0.4 \mathrm{~m}$ and $0.6 \mathrm{~m}$ in the simultaneous fracturing under the hydrostatic pressure condition $\left(\sigma_{\mathrm{v}}=\sigma_{\mathrm{h}}=30 \mathrm{MPa}\right)$.
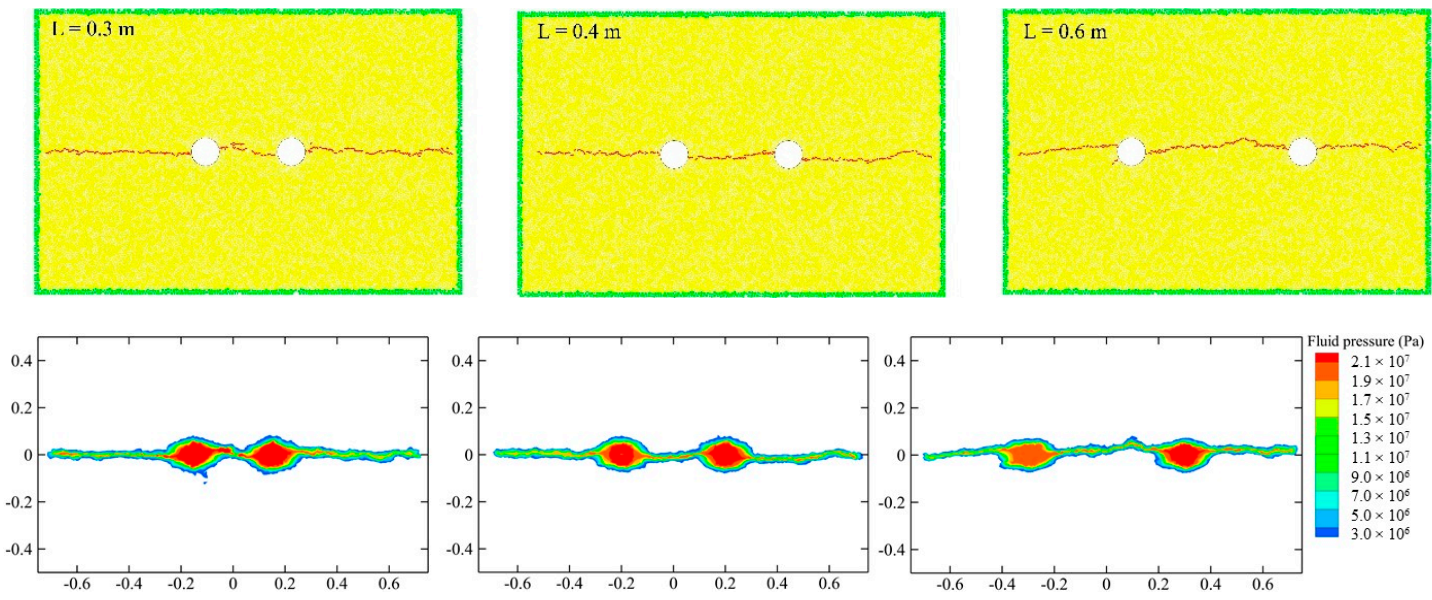

Figure 16. The crack spatial distributions and corresponding fluid pressure fields for the two-well granite models with the well spacing of $0.3 \mathrm{~m}, 0.4 \mathrm{~m}$ and $0.6 \mathrm{~m}$ in the simultaneous fracturing under the in-situ differential stress condition $\left(\sigma_{\mathrm{v}}=15 \mathrm{MPa}\right.$ and $\left.\sigma_{\mathrm{h}}=30 \mathrm{MPa}\right)$.

Under the hydrostatic pressure condition, the hydraulic fractures in these models exhibit the interesting propagation patterns. When $\mathrm{L}=0.3 \mathrm{~m}$, plenty of microcracks initiated around the Well No.1 and Well No.2. Two hydraulic fractures extended along the horizontal direction and merged into one fracture in the middle of the model. The fracturing fluid injected into Well No.1 flowed towards Well No.2 through the hydraulic fracture and assisted the hydraulic fracture on the right side of Well No.2 to extend to the model boundary, while other microcracks near Well No.1 were not allowed to further extend owing to insufficient fluid pressure. When $\mathrm{L}=0.4 \mathrm{~m}$, the hydraulic fractures initiated from the micro defects on the surface of the two wells extended along the initial directions of different heights and deflected to each other. Until the fracture from Well No.1 reached the bottom of Well No.2 and the fracture from Well No.2 was arrested by the fracture from Well No.1, the two wells were more closely connected. Counting the hydraulic fracture extending to the right edge, three fracture branches were developed in the model. When $\mathrm{L}=0.5 \mathrm{~m}$, the hydraulic fractures between the two wells were also distorted, but did not meet before the simulation stopped as a consequence of the larger well spacing. When the well spacing grew to $0.6 \mathrm{~m}$, only two hydraulic fractures extended to the left and right edges of the model, and the microcracks between the two wells stagnated. 
Under the in-situ differential stress condition, each model after fracturing had the similar propagation pattern for fractures. Initially, four fractures extended horizontally from both sides of the two injection wells. Then the two hydraulic fractures between the wells merged into one fracture. Finally, three major fracture branches crossed the whole model. With the increase of well spacing, the micro defects around the wells control the crack initiation, thereby creating the hydraulic fractures at the different heights to merge after deflection.

The representative fluid pressures and crack information for the models with different well spacing after the fracturing are listed in Table 4. Before the continuous propagation of hydraulic fractures, there were too few microcracks to build the hydraulic connection between the two wells. Not surprisingly, the breakdown pressures under the same in-situ stress condition for these models remained steady as the well spacing changes. By contrast, a positive correlation was found between well spacing and fracture propagation pressure under the hydrostatic pressure condition. In the fracturing of the models with small well spacing, due to the superposition of the leaking fluid in the middle of the model, the effective stress of the rock matrix in this region and the fluid pressure required for hydraulic fracture propagation were correspondingly reduced. Obviously, this superimposed effect of fluid was suppressed when the well spacing was set larger. In addition, this phenomenon of fracture propagation pressure had not been monitored when the hydraulic fractures were controlled by the maximum horizontal in-situ stress. Taken together, these results suggest that there is an association between well spacing and fracture branches. Too small or too large well spacing makes it difficult to construct complex fracture networks in the reservoir. Relatively speaking, to ensure the hydraulic fractures to extend in the area between the two wells, the well spacing under the hydrostatic pressure may be smaller than that under the in-situ differential stress.

Table 4. Summary of the Fracturing Characteristics for the Two-Well Granite Model with Different Well Spacing under the Simultaneous Fracturing.

\begin{tabular}{|c|c|c|c|c|c|c|c|}
\hline $\begin{array}{l}\text { In-Situ Stress } \\
\text { Conditions }\end{array}$ & $\begin{array}{l}\text { Hydraulic Fracturing } \\
\text { Characteristics }\end{array}$ & \multicolumn{2}{|c|}{$\mathrm{L}=0.3 \mathrm{~m}$} & \multicolumn{2}{|c|}{$\mathrm{L}=0.4 \mathrm{~m}$} & \multicolumn{2}{|c|}{$\mathrm{L}=0.6 \mathrm{~m}$} \\
\hline \multirow{3}{*}{$\begin{array}{l}\sigma_{\mathrm{v}}=30 \mathrm{MPa} \\
\sigma_{\mathrm{h}}=30 \mathrm{MPa}\end{array}$} & $\begin{array}{l}\text { Breakdown pressure } \\
(\mathrm{MPa})\end{array}$ & 62.3 & 61.6 & 60.1 & 59.2 & 61.8 & 62.4 \\
\hline & $\begin{array}{c}\text { Fracture extension } \\
\text { pressure }(\mathrm{MPa})\end{array}$ & 36.9 & 37.2 & 38.2 & 40.1 & 45.6 & 46.5 \\
\hline & Crack number & \multicolumn{2}{|c|}{138} & \multicolumn{2}{|c|}{150} & \multicolumn{2}{|c|}{118} \\
\hline \multirow{4}{*}{$\begin{array}{l}\sigma_{\mathrm{v}}=15 \mathrm{MPa} \\
\sigma_{\mathrm{h}}=30 \mathrm{MPa}\end{array}$} & $\begin{array}{l}\text { Breakdown pressure } \\
(\mathrm{MPa})\end{array}$ & 39.8 & 37.4 & 40.2 & 38.7 & 40.6 & 39.9 \\
\hline & $\begin{array}{l}\text { Fracture extension } \\
\text { pressure }(\mathrm{MPa})\end{array}$ & 21.2 & 20.9 & 21.0 & 21.1 & 20.8 & 22.8 \\
\hline & Crack number & \multicolumn{2}{|c|}{179} & \multicolumn{2}{|c|}{160} & \multicolumn{2}{|c|}{163} \\
\hline & $\begin{array}{l}\text { Hydraulic fracture } \\
\text { branches }\end{array}$ & \multicolumn{2}{|c|}{3} & \multicolumn{2}{|c|}{3} & \multicolumn{2}{|c|}{3} \\
\hline
\end{tabular}

\section{Analysis of Stress Shadow Effect}

The fluid net pressure during the propagation of hydraulic fractures has contributed to the increase in the stress of the rock matrix around the fractures along the height direction. This important behavior of fractures is defined as "stress shadow effect", which has non-negligible impacts on the extension directions, opening degrees and shapes [66-68]. Especially in the situation of multiple injection wells in the reservoir, the interaction of the stress shadows for the adjacent hydraulic fractures becomes more intense and complicated.

However, discrete particle elements in the DEM suppress the direct expression of continuum physical quantities including stress and strain rate. The measurement circle is a monitoring mechanism built in PFC software to describe these quantities in a specified circular area by tracking the forces and displacements of particles and their related contacts. Therefore, the measurement circles densely distributed in the model realize the transition from the discrete physical quantities in the micro scale 
to the continuous ones in the macro scale. In order to obtain the rich data of measurement points, a total of 14,751 measurement circles with a radius of $0.01 \mathrm{~m}$ were regularly arranged in 99 rows and 149 columns to cover each two-well fracturing model (Figure $8 b$ ). The stress distributions of the models after fracturing were compared with their initial states without fluid injection to obtain the final stress increments.

Typical vertical stress increment distributions $\left(\Delta \sigma_{\mathrm{y}}\right)$ under different injection sequence and well spacing conditions are presented in Figures 17 and 18, respectively. All the models demonstrated a noticeable rise in the vertical stress on the upper and lower outer sides of the hydraulic fractures, which was in line with the basic law of stress shadow effect and proved the reliability of the modified fluid-mechanical coupling algorithm again. These vertical stress increments gradually decreased with the increasing distances to the fractures. In the area near the model boundaries, the vertical stress was roughly unchanged. Nevertheless, in the small area closest to the hydraulic fractures, the vertical stress was reduced rather than increased because of the leakage of fluid into the rock matrix. The injection of fluid led to an evident increase of vertical stress in the area around the wells without hydraulic fractures as well, which was higher than that caused by the hydraulic fractures.

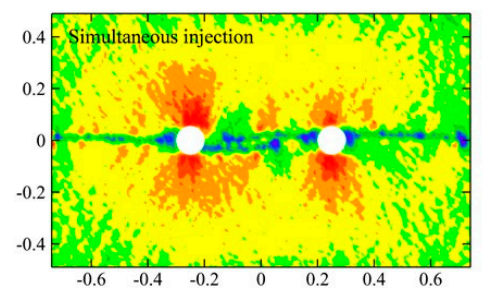

(a)

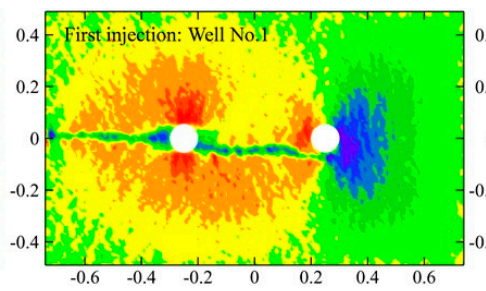

(b)

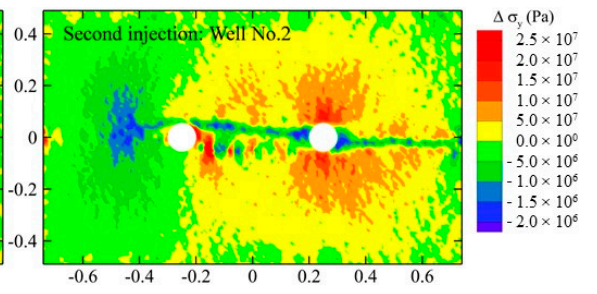

(c)

Figure 17. Vertical stress increment distributions for the two-well granite model with the well spacing of $0.5 \mathrm{~m}$ under different injection sequences when $\sigma_{\mathrm{v}}=15 \mathrm{MPa}$ and $\sigma_{\mathrm{h}}=30 \mathrm{MPa}$ : (a) simultaneous fracturing; (b) first injection in Well No.1; and (c) second injection in Well No.2.

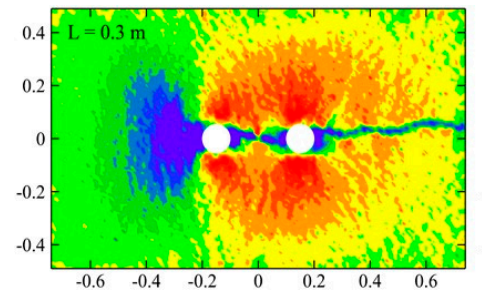

(a)

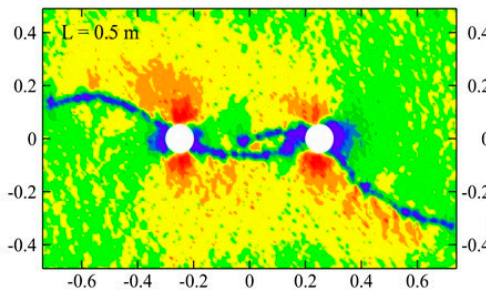

(b)

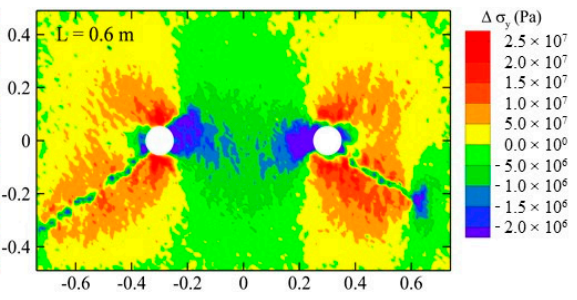

(c)

Figure 18. Vertical stress increment distributions for the two-well granite models with the different well spacing in the simultaneous fracturing when $\sigma_{\mathrm{v}}=30 \mathrm{MPa}$ and $\sigma_{\mathrm{h}}=30 \mathrm{MPa}$ : (a) $\mathrm{L}=0.3 \mathrm{~m} ;(\mathbf{b}) \mathrm{L}=0.5 \mathrm{~m}$; and (c) $\mathrm{L}=0.6 \mathrm{~m}$.

More concretely, the injection sequence and well spacing are the dominant factors in the stress shadow effect. For the simultaneous fracturing when $\sigma_{\mathrm{v}}=15 \mathrm{MPa}$ and $\sigma_{\mathrm{h}}=30 \mathrm{MPa}$ (Figure 17a), no expected superposition of the stress shadow effects existed between the two adjacent hydraulic fractures. Under such superposition effect, the two parallel hydraulic fractures would repel each other and progressively separate [69]. A possible explanation for this is that the tensile stress fields at the fracture tips and the fluid leakage effect both acted on the area between the two fractures, which diminished the vertical stress and promoted the mutual attraction of fractures. Excluding this area, the superposition effect of stress shadows was widely scattered in the middle of the model. For the first injection in Well No.1 (Figure 17b), a large range of vertical compressive stress declined at the tip of fracture on the right side of Well No.2, resulting from the concentration of tensile stress and 
the climb of pore fluid pressure. The initial compressive stress state in the model have been altered into the tensile stress state near the fracture tip, whereas the decrease of vertical stress in the region far from the tip may not satisfy the alteration of stress state. For the second injection in Well No.2 (Figure 17c), the stress shadow effect of the hydraulic fractures around Well No.1 was weakened stemming from the removal of preceding fluid and the primary vertical stress increment encompassed Well No.2. As a consequence, the new hydraulic fracture did not deflect to the old one, but moved away. The comparison of the fracturing under different injection sequences reveals that the influence range of stress shadow effect in simultaneous fracturing exceeds that in asynchronous fracturing.

When $\sigma_{\mathrm{v}}=30 \mathrm{MPa}$ and $\sigma_{\mathrm{h}}=30 \mathrm{MPa}$, under the condition of small well spacing (Figure 18a), the superposition of stress shadow effect between the two injection wells enhanced greatly and restricted the initiation of hydraulic fractures in other directions. As the well spacing was slightly increased (Figure 18b), the superposition range of stress shadow effect reduced and the high vertical stress on the upper and lower sides of the wells prohibited the fractures in the middle of the model from twisting outwards. When $\mathrm{L}=0.6 \mathrm{~m}$ (Figure 18c), no interaction between the stress shadow effects was produced by different fractures. Therefore, the superposition degree of stress shadow effects between the two wells is in inverse proportion to their well spacing.

\section{Discussion and Conclusions}

The two-dimensional fluid-mechanical coupling algorithm in PFC has been extensively used to study the flow of fracturing fluid in rock, hydraulic fracture propagation and induced seismicity $[33,35-47,53-55]$. In theory, it is practicable to conduct the two-dimensional simplified treatment for the relatively homogeneous and isotropic rocks in the macro scale, for the reason that the two-dimensional models can be regarded as a section of the real three-dimensional domains. Furthermore, two-dimensional simulation has the advantages of simple pre-processing, efficient calculation and intuitive results presentation in solving certain specific problems compared with three-dimensional simulation.

In this paper, the two-dimensional numerical models of Alxa porphyritic granites were strictly generated in PFC based on the PBM and the modified fluid-mechanical coupling algorithm. The micro input parameters in these models were effectively calibrated by the laboratory test results. Moreover, the accuracy of injection-induced fracturing was validated against the analytical solutions. A series of simulations for hydraulic fracturing in two-well granite models were performed to investigate the influences of injection sequence and well spacing on the breakdown pressure, fracture propagation pressure, fracture propagation pattern and stress shadow. The main results of this study are summarized as follows:

(1) The injection sequence and well spacing have significant effects on the fracture propagation pressure instead of the breakdown pressure. Under the condition of hydrostatic pressure, lower fracture propagation pressure is required by the simultaneous fracturing models or small well spacing models. But these effects generally decay as the vertical in-situ stress declines.

(2) Adjusting the injection sequence is a feasible way to control the propagation direction of hydraulic fractures. In the state of hydrostatic pressure, simultaneous fracturing allows more fracturing fluid to penetrate into the surrounding rock and compels the fractures to deflect to the horizontal direction, which is beneficial for the formation of complex fracture networks between the injection wells. The initial expansion of the fractures in asynchronous fracturing is easily disturbed by the micro defects around the boreholes, largely engendering no fractures between these wells. When the maximum in-situ stress is in the horizontal direction, in contrast to the asynchronous fracturing, simultaneous fracturing intensifies the coalescence of horizontal fractures.

(3) The reasonable well spacing in the reservoir affects the growth of fracture branches. Excessively small or large well spacing limits the generation of multiple fracture branches in fracture networks. Comparatively speaking, for getting more fractures between the injection wells, the 
expected well spacing under the hydrostatic pressure may be smaller than that under the in-situ differential stress.

(4) The stress shadow effects of hydraulic fractures are also closely related to the injection sequence and well spacing. In the case of simultaneous fracturing or small well spacing, the superposition of the stress shadow effects in the middle of the model strengthens their impact. When the fluid injection decreases or the well spacing increases, this superposition will be suppressed.

In summary, the findings of this study not only reveal the propagation and interaction mechanisms of hydraulic fractures in multi-well fracturing, but also provide valuable reference for the optimization of fracturing technology in field production. However, the two-dimensional models still have an inevitable defect, that is, the hydraulic fractures are forced to expand in the selected section, which fails to represent the three-dimensional expansion patterns. Further works associated with the two-dimensional and three-dimensional multi-well fracturing simulations, such as the interaction between hydraulic and natural fractures, the temperature effect of fracturing fluid, and the proppant migration, should be involved in future research.

Author Contributions: Conceptualization, L.Z. and J.Z.; methodology, S.W.; software, J.Z.; validation, S.W. and Z.H.; investigation, S.W.; resources, L.Z.; data curation, Z.H.; writing-original draft preparation, S.W.; writing-review and editing, J.Z.; visualization, S.W.; supervision, L.Z. All authors have read and agreed to the published version of the manuscript.

Funding: This research was funded by the National Natural Science Foundation of China (Grant Nos. 41672321, 41972287, 41572312), China Postdoctoral Science Foundation (Grant Nos. 2018M630204, 2019T120133) and National Key Research and Development Program (Grant No.2018YFB1501801).

Conflicts of Interest: The authors declare no conflict of interest.

\section{References}

1. Yuan, B.; Wood, D.A. A holistic review of geosystem damage during unconventional oil, gas and geothermal energy recovery. Fuel 2018, 227, 99-110. [CrossRef]

2. Soeder, D.J. The successful development of gas and oil resources from shales in North America. J. Pet. Sci. Eng. 2018, 163, 399-420. [CrossRef]

3. Kumari, W.G.P.; Ranjith, P.G.; Perera, M.S.A.; Li, X.; Li, L.H.; Chen, B.K.; Isaka, B.L.A.; De Silva, V.R.S. Hydraulic fracturing under high temperature and pressure conditions with micro $\mathrm{CT}$ applications: Geothermal energy from hot dry rocks. Fuel 2018, 230, 138-154. [CrossRef]

4. Li, F.; Yuan, Q.; Li, T.; Li, Z.; Sun, C.; Chen, G. A review: Enhanced recovery of natural gas hydrate reservoirs. Chin. J. Chem. Eng. 2019, 27, 2062-2073. [CrossRef]

5. Yang, Y.; Wang, K.; Zhang, L.; Sun, H.; Zhang, K.; Ma, J. Pore-scale simulation of shale oil flow based on pore network model. Fuel 2019, 251, 683-692. [CrossRef]

6. Li, H.; Zhou, L.; Lu, Y.; Yan, F.; Zhou, J.; Tang, J. Changes in Pore Structure of Dry-hot Rock with Supercritical $\mathrm{CO}_{2}$ Treatment. Energy Fuels 2020, 34, 6059-6068. [CrossRef]

7. Warpinski, N.R. Hydraulic fracturing in tight, fissured media. J. Pet. Technol. 1991, 43. [CrossRef]

8. Osiptsov, A.A. Fluid Mechanics of Hydraulic Fracturing: A Review. J. Pet. Sci. Eng. 2017, 156, 513-535. [CrossRef]

9. Patel, S.M.; Sondergeld, C.H.; Rai, C.S. Laboratory studies of hydraulic fracturing by cyclic injection. Int. J. Rock Mech. Min. Sci. 2017, 95, 8-15. [CrossRef]

10. Yang, T.H.; Tham, L.G.; Tang, C.A.; Liang, Z.Z.; Tsui, Y. Influence of heterogeneity of mechanical properties on hydraulic fracturing in permeable rocks. Rock Mech. Rock Eng. 2004, 37, 251-275. [CrossRef]

11. Yarushina, V.M.; Bercovici, D.; Oristaglio, M.L. Rock deformation models and fluid leak-off in hydraulic fracturing. Geophys. J. Int. 2013, 194, 1514-1526. [CrossRef]

12. Dahi Taleghani, A.; Gonzalez, M.; Shojaei, A. Overview of numerical models for interactions between hydraulic fractures and natural fractures: Challenges and limitations. Comput. Geotech. 2016, 71, 361-368. [CrossRef] 
13. Huang, L.; Liu, J.; Zhang, F.; Dontsov, E.; Damjanac, B. Exploring the influence of rock inherent heterogeneity and grain size on hydraulic fracturing using discrete element modeling. Int. J. Solids Struct. 2019, 176-177, 207-220. [CrossRef]

14. Ishida, T.; Aoyagi, K.; Niwa, T.; Chen, Y.; Murata, S.; Chen, Q.; Nakayama, Y. Acoustic emission monitoring of hydraulic fracturing laboratory experiment with supercritical and liquid $\mathrm{CO}_{2}$. Geophys. Res. Lett. $2012,39$. [CrossRef]

15. Bennour, Z.; Watanabe, S.; Chen, Y.; Ishida, T.; Akai, T. Evaluation of stimulated reservoir volume in laboratory hydraulic fracturing with oil, water and liquid carbon dioxide under microscopy using the fluorescence method. Geomech. Geophys. Geo-Energy Geo-Resour. 2018, 4, 39-50. [CrossRef]

16. Gonçalves da Silva, B.; Einstein, H. Physical processes involved in the laboratory hydraulic fracturing of granite: Visual observations and interpretation. Eng. Fract. Mech. 2018, 191, 125-142. [CrossRef]

17. Li, B.Q.; Gonçalves da Silva, B.; Einstein, H. Laboratory hydraulic fracturing of granite: Acoustic emission observations and interpretation. Eng. Fract. Mech. 2019, 209, 200-220. [CrossRef]

18. Guo, T.; Zhang, S.; Qu, Z.; Zhou, T.; Xiao, Y.; Gao, J. Experimental study of hydraulic fracturing for shale by stimulated reservoir volume. Fuel 2014, 128, 373-380. [CrossRef]

19. Zhang, X.; Lu, Y.; Tang, J.; Zhou, Z.; Liao, Y. Experimental study on fracture initiation and propagation in shale using supercritical carbon dioxide fracturing. Fuel 2017, 190, 370-378. [CrossRef]

20. He, J.; Li, X.; Yin, C.; Zhang, Y.; Lin, C. Propagation and characterization of the micro cracks induced by hydraulic fracturing in shale. Energy 2020, 191, 116449. [CrossRef]

21. Zhuang, L.; Jung, S.G.; Diaz, M.; Kim, K.Y.; Hofmann, H.; Min, K.B.; Zang, A.; Stephansson, O.; Zimmermann, G.; Yoon, J.S. Laboratory True Triaxial Hydraulic Fracturing of Granite Under Six Fluid Injection Schemes and Grain-Scale Fracture Observations. Rock Mech. Rock Eng. 2020, 1-16. [CrossRef]

22. Jing, L. A review of techniques, advances and outstanding issues in numerical modelling for rock mechanics and rock engineering. Int. J. Rock Mech. Min. Sci. 2003, 40, 283-353. [CrossRef]

23. Jing, L.; Hudson, J.A. Numerical methods in rock mechanics. Int. J. Rock Mech. Min. Sci. 2002, 39, 409-427. [CrossRef]

24. Zhang, Y.; Wong, L.N.Y. A review of numerical techniques approaching microstructures of crystalline rocks. Comput. Geosci. 2018, 115, 167-187. [CrossRef]

25. Li, J.; Dong, S.; Hua, W.; Li, X.; Pan, X. Numerical investigation of hydraulic fracture propagation based on cohesive zone model in naturally fractured formations. Processes 2019, 7, 28. [CrossRef]

26. Liao, J.; Hou, M.Z.; Mehmood, F.; Feng, W. A 3D approach to study the interaction between hydraulic and natural fracture. Environ. Earth Sci. 2019, 78, 1-18. [CrossRef]

27. Zangeneh, N.; Eberhardt, E.; Bustin, R.M.; Bustin, A. A numerical investigation of fault slip triggered by hydraulic fracturing. In Proceedings of the ISRM International Conference for Effective and Sustainable Hydraulic Fracturing, Brisbane, Australia, 20-22 May 2013; pp. 477-488. [CrossRef]

28. Janiszewski, M.; Shen, B.; Rinne, M. Simulation of the interactions between hydraulic and natural fractures using a fracture mechanics approach. J. Rock Mech. Geotech. Eng. 2019, 11, 1138-1150. [CrossRef]

29. Potyondy, D.O.; Cundall, P.A. A bonded-particle model for rock. Int. J. Rock Mech. Min. Sci. 2004, 41, 1329-1364. [CrossRef]

30. Hazzard, J.F.; Young, R.P.; Maxwell, S.C. Micromechanical modeling of cracking and failure in brittle rocks. J. Geophys. Res. Solid Earth 2000, 105, 16683-16697. [CrossRef]

31. Fakhimi, A.; Carvalho, F.; Ishida, T.; Labuz, J.F. Simulation of failure around a circular opening in rock. Int. J. Rock Mech. Min. Sci. 2002, 39, 507-515. [CrossRef]

32. Shan, P.; Lai, X. Mesoscopic structure PFC 2D model of soil rock mixture based on digital image. J. Vis. Commun. Image Represent. 2019, 58, 407-415. [CrossRef]

33. Liu, G.; Sun, W.C.; Lowinger, S.M.; Zhang, Z.H.; Huang, M.; Peng, J. Coupled flow network and discrete element modeling of injection-induced crack propagation and coalescence in brittle rock. Acta Geotech. 2019, 14, 843-868. [CrossRef]

34. Cundall, P.A. Fluid Formulation for PFC2D; Itasca Consulting Group: Minneapolis, MN, USA, 2000.

35. Al-Busaidi, A.; Hazzard, J.F.; Young, R.P. Distinct element modeling of hydraulically fractured Lac du Bonnet granite. J. Geophys. Res. Solid Earth 2005, 110, 1-14. [CrossRef] 
36. Yoon, J.; Backers, T.; Dresen, G. Prototype PFC2D model for simulation of hydraulic fracturing and induced seismicity. In Proceedings of the ISRM International Symposium-EUROCK, Stockholm, Sweden, 28-30 May 2012.

37. Yoon, J.S.; Zimmermann, G.; Zang, A. Discrete element modeling of cyclic rate fluid injection at multiple locations in naturally fractured reservoirs. Int. J. Rock Mech. Min. Sci. 2015, 74, 15-23. [CrossRef]

38. Yoon, J.S.; Zimmermann, G.; Zang, A.; Stephansson, O. Discrete element modeling of fluid injection-induced seismicity and activation of nearby fault. Can. Geotech. J. 2015, 52, 1457-1465. [CrossRef]

39. Tomac, I.; Gutierrez, M. Coupled hydro-thermo-mechanical modeling of hydraulic fracturing in quasi-brittle rocks using BPM-DEM. J. Rock Mech. Geotech. Eng. 2017, 9, 92-104. [CrossRef]

40. Tomac, I.; Gutierrez, M. Micromechanics of Hydro-Thermo-Mechanical Processes in Rock Accounting for Thermal Convection. J. Eng. Mech. 2019, 145. [CrossRef]

41. Zhou, J.; Zhang, L.; Han, Z. Hydraulic fracturing process by using a modified two-dimensional particle flow code-method and validation. Prog. Comput. Fluid Dyn. 2017, 17, 52-62. [CrossRef]

42. Zhang, L.; Zhou, J.; Han, Z. Hydraulic fracturing process by using a modified two-dimensional particle flow code-case study. Prog. Comput. Fluid Dyn. 2017, 17, 13-26. [CrossRef]

43. Zhou, J.; Zhang, L.; Braun, A.; Han, Z. Numerical Modeling and Investigation of Fluid-Driven Fracture Propagation in Reservoirs Based on a Modified Fluid-Mechanically Coupled Model in Two-Dimensional Particle Flow Code. Energies 2016, 9, 699. [CrossRef]

44. Zhou, J.; Zhang, L.; Pan, Z.; Han, Z. Numerical investigation of fluid-driven near-borehole fracture propagation in laminated reservoir rock using PFC2D. J. Nat. Gas Sci. Eng. 2016, 36, 719-733. [CrossRef]

45. Zhou, J.; Zhang, L.; Pan, Z.; Han, Z. Numerical studies of interactions between hydraulic and natural fractures by Smooth Joint Model. J. Nat. Gas Sci. Eng. 2017, 46, 592-602. [CrossRef]

46. Zhou, J.; Zhang, L.; Braun, A.; Han, Z. Investigation of processes of interaction between hydraulic and natural fractures by PFC modeling comparing against laboratory experiments and analytical models. Energies 2017, 1001. [CrossRef]

47. Zhang, L.; Zhou, J.; Braun, A.; Han, Z. Sensitivity analysis on the interaction between hydraulic and natural fractures based on an explicitly coupled hydro-geomechanical model in PFC2D. J. Pet. Sci. Eng. 2018, 167, 638-653. [CrossRef]

48. Itasca Consulting Group Inc. Manual PFC2D (Particle Flow Code); Version 4.0 Users' Guide; Itasca Consulting Group Inc.: Minneapolis, MN, USA, 2008.

49. Cho, N.; Martin, C.D.; Sego, D.C. A clumped particle model for rock. Int. J. Rock Mech. Min. Sci. 2007, 44, 997-1010. [CrossRef]

50. Wu, S.; Xu, X. A Study of Three Intrinsic Problems of the Classic Discrete Element Method Using Flat-Joint Model. Rock Mech. Rock Eng. 2016, 49, 1813-1830. [CrossRef]

51. Potyondy, D.O. Parallel-Bond Refinements to Match Macroproperties of Hard Rock. In Proceedings of the 2nd FLAC/DEM Symposium, Melbourne, Australia, 14-16 February 2011.

52. Ding, X.; Zhang, L. A new contact model to improve the simulated ratio of unconfined compressive strength to tensile strength in bonded particle models. Int. J. Rock Mech. Min. Sci. 2014, 69, 111-119. [CrossRef]

53. Yoon, J.S.; Zang, A.; Stephansson, O. Numerical investigation on optimized stimulation of intact and naturally fractured deep geothermal reservoirs using hydro-mechanical coupled discrete particles joints model. Geothermics 2014, 52, 165-184. [CrossRef]

54. Han, Z.; Zhou, J.; Zhang, L. Influence of grain size heterogeneity and in-situ stress on the hydraulic fracturing process by PFC2D Modeling. Energies 2018, 11, 1413. [CrossRef]

55. Zhao, X.; Paul Young, R. Numerical modeling of seismicity induced by fluid injection in naturally fractured reservoirs. Geophysics 2011, 76. [CrossRef]

56. Yoon, J. Application of experimental design and optimization to PFC model calibration in uniaxial compression simulation. Int. J. Rock Mech. Min. Sci. 2007, 44, 871-889. [CrossRef]

57. Schöpfer, M.P.J.; Childs, C.; Walsh, J.J. Two-dimensional distinct element modeling of the structure and growth of normal faults in multilayer sequences: 1 . Model calibration, boundary conditions, and selected results. J. Geophys. Res. Solid Earth 2007, 112. [CrossRef]

58. Ajamzadeh, M.R.; Sarfarazi, V.; Haeri, H.; Dehghani, H. The effect of micro parameters of PFC software on the model calibration. Smart Struct. Syst. 2018, 22, 643-662. [CrossRef] 
59. Wang, Y.; Tonon, F. Modeling Lac du Bonnet granite using a discrete element model. Int. J. Rock Mech. Min. Sci. 2009, 46, 1124-1135. [CrossRef]

60. Zhou, J.; Zhang, L.; Yang, D.; Braun, A.; Han, Z. Investigation of the quasi-brittle failure of alashan granite viewed from laboratory experiments and grain-based discrete element modeling. Materials 2017, 10, 835. [CrossRef]

61. Zhou, J.; Lan, H.; Zhang, L.; Yang, D.; Song, J.; Wang, S. Novel grain-based model for simulation of brittle failure of Alxa porphyritic granite. Eng. Geol. 2019, 251, 100-114. [CrossRef]

62. Haimson, B.; Fairhurst, C. Initiation and Extension of Hydraulic Fractures in Rocks. Soc. Pet. Eng. J. 1967, 7, 310-318. [CrossRef]

63. Hubbert, M.K.; Willis, D.G. Mechanics of Hydraulic Fracturing. Pet. Trans. Aime. 1957, 210, $153-168$. [CrossRef]

64. Mao, R.; Feng, Z.; Liu, Z.; Zhao, Y. Laboratory hydraulic fracturing test on large-scale pre-cracked granite specimens. J. Nat. Gas Sci. Eng. 2017, 44, 278-286. [CrossRef]

65. Xing, Y.; Zhang, G.; Luo, T.; Jiang, Y.; Ning, S. Hydraulic fracturing in high-temperature granite characterized by acoustic emission. J. Pet. Sci. Eng. 2019, 178, 475-484. [CrossRef]

66. Germanovich, L.N.; Astakhov, D.K. Fracture closure in extension and mechanical interaction of parallel joints. J. Geophys. Res. Solid Earth 2004, 109. [CrossRef]

67. Olson, J.E. Multi-fracture propagation modeling: Applications to hydraulic fracturing in shales and tight gas sands. In Proceedings of the 42nd US Rock Mechanics Symposium and 2nd US-Canada Rock Mechanics Symposium, San Francisco, CA, USA, 29 June-2 July 2008.

68. Zhou, L.; Chen, J.; Gou, Y.; Feng, W. Numerical investigation of the time-dependent and the proppant dominated stress shadow effects in a transverse multiple fracture system and optimization. Energies 2017, 10, 83. [CrossRef]

69. Zhang, X.; Jeffrey, R.G.; Thiercelin, M. Deflection and propagation of fluid-driven fractures at frictional bedding interfaces: A numerical investigation. J. Struct. Geol. 2007, 29, 396-410. [CrossRef]

(C) 2020 by the authors. Licensee MDPI, Basel, Switzerland. This article is an open access article distributed under the terms and conditions of the Creative Commons Attribution (CC BY) license (http://creativecommons.org/licenses/by/4.0/). 